\title{
Good Times, Bad Times: Innovation and Survival over the Business Cycle
}

\author{
Elena Cefis* \\ Dep. Of Management, Economics and Quantitative Methods, University of Bergamo, via dei \\ Caniana 2, 24127 Bergamo, Italy. \\ Institute of Economics, Sant'Anna School of Advanced Studies, Piazza Martiri della Libertà, \\ 33, 56127 Pisa, Italy \\ Email: elena.cefis@unibg.it
}

\author{
Orietta Marsili \\ School of Management, University of Bath, \\ Bath BA2 7AY, U.K. \\ o.marsili@bath.ac.uk
}

This version: 5 November 2018

\begin{abstract}
In times of crisis, policy makers call upon entrepreneurship as a remedy to an economic downturn. Yet, at these times new firms face intensified selection and survival hinges on heterogeneous capabilities. We examine how the founding innovative capabilities of new ventures created in the Netherlands in 2001-2006 affected their survival likelihood before, during and after the 2007-2008 global financial crisis. We estimate a piecewise exponential model linking survival times, from 2001 to 2015, to longitudinal innovation data from the Community Innovation Survey (CIS). New firms innovating within two years from their founding enjoy a long-term adaptive survival premium during and after the crisis. This premium and its duration over the stages of the crisis are contingent to the form of innovation: technological innovations entail a more effective and enduring premium, as compared to non-technological innovations, which can be even detrimental for survival.
\end{abstract}

JEL CODE: L11; L25; D21; O32

Keywords: firm survival; environmental jolts; financial crisis; organisational adaptation; technological and non-technological innovation.

Accepted for publication in Industrial and Corporate Change, DOI: 10.1093/icc/dty072

\footnotetext{
* Main author for correspondence
}

\section{Acknowledgments:}

The authors thank Alessandro Lucini-Paioni for invaluable research assistance, and the participants at International ICC Conference: Beyond Technological Innovation and Diffusion. University of Berkely, Berkeley, CA, U.S.A., December 11-14, 2016; CONCORDì 2017 - 10 Years 2007-2017 Conference, Innovation and Industrial Dynamics: challenges for the next decade; JRC - European Commission and OECD, Seville, Spain, September 27-29, 2017; Workshop SIEPI 2018, February 1-2, 2018, Ferrara, Italy; 2018 BCERC, June 6-9, 2018, Waterford, Ireland; AoM Annual Meeting, August 10-14, 2018, Chicago, Illinois; ACSB - Asian SME Conference, September 10-13, 2018, Tokyo, Japan; and the participants at the seminar in University of Bergamo, April 2018. The empirical part of this research was carried out at Microdata - Centraal Bureau voor Statistiek (CBS), the Netherlands. The views expressed in this paper are those of the authors and do not necessarily reflect the policies of Statistics Netherlands. Elena Cefis acknowledges financial support from the University of Bergamo (grants ex 60\%, n. 60CEFI15 and n. 60CEFI17, Dept. of Management, Economics, and Quantitative Methods). 


\section{Introduction}

Unexpected and disruptive events such as the global financial crisis create an extreme and perilous environment for firms. These events, or environmental jolts, produce a variety of responses by firms, leading to the survival of some and not of others (Meyer, 1982). The scope for a response by firms is bound by their resources, at three levels (Agarwal et al., 2009). First, organisations differ in the resources they directly control. The immediate effect of a financial crisis is to impose tighter liquidity and resource constraints, which lower survival (Clarke et al., 2012). Second, organisations differ in resources they do not directly control but can access by ownership relationships with other organisations. Environmental jolts alter the odds of survival of companies that differ in ownership structure and control: independent firms versus subsidiaries (Bradley et al., 2011a), multinational versus local subsidiaries (Alfaro and Chen, 2012) and family-controlled versus non-family controlled firms (Lins et al., 2013). Third, organisations differ in the ability to leverage and reconfigure resources, either internally or externally controlled, in the effort to adapt to changes in the environment, what has labelled as adaptive capabilities (Augier and Teece, 2009). These represent a subset of dynamic capabilities (Augier and Teece, 2009) as they relate to the adaptive behaviour of firms in the face of external changes that are sudden and extreme (Grewal and Tansuhaj, 2001; Makkonen et al., 2014).

Earlier studies on survival during environmental jolts illustrate the implications of firm-specific investment decisions and ownership structure (Alfaro and Chen, 2012; Bradley et al., 2011a; Clarke et al., 2012). Less is known about heterogeneous adaptive capabilities. Hence, we ask which types of capability act as adaptive capabilities to an external shock such as the global financial crisis. In particular, we focus on the innovative capabilities of new firms, because new firms are the most exposed to the clear and present danger of the crisis. Studies examining firm survival in the years preceding the global financial crisis of 2007- 
2009 show that entrepreneurial firms, while facing liabilities of newness and smallness (Aldrich and Fiol, 1994), are also those that most benefit of an 'innovation premium' for survival (Cefis and Marsili, 2006), which enhances their survival probabilities. Building on this evidence, we are interested in whether innovation not only provides a survival premium in the good times but also equip new firms of adaptive capabilities for the bad times. To answer this question, we draw on evolutionary economics (Nelson and Winter, 1982). We propose that new firms that innovate at the time of the founding build distinctive and longlasting adaptive capabilities, which increase their chances of survival to environmental jolts. We also argue that adaptive capabilities vary by type of innovation in a hierarchical order of criticality, comparing technological innovations, in products and processes, to managerial innovations, in organisational and marketing practices (Ballot et al., 2015; Battisti and Stoneman, 2010; Mol and Birkinshaw, 2009).

In this study, we observe the survival likelihood over the time from 2001 to 2015, for a sample of 2329 new firms created in the Netherlands from 2001 to 2006 . For this sample, by using data from the Community Innovation Survey (CIS), we examine how the innovative capabilities at the time of the founding influence the likelihood of survival before, during and after the 2007-2008 financial crisis. We find that product innovation is a primary source of survival during and after the crisis; process innovation has a short-lived positive effect during the crisis; organisational innovation and marketing innovation are ancillary or even detrimental. We conclude that early capabilities in product innovation, more than in other types of managerial innovations, are critical for building long-term resilience.

Our study contributes to the understanding of organisational adaptation in relation to the entrepreneurial process. We highlight how organisational adaptation is shaped by founding conditions, by the early ability of new firms to innovate, at a time in which the uncertainty of innovation is compounded with the uncertainty of organisational creation. Our 
study responds to the call made by management scholars and economists to study the impact of the global financial crisis from a microeconomic perspective, in contrast to the more diffuse macroeconomic approach (Agarwal et al., 2009; Alfaro and Chen, 2012).

Understanding the sources of organisational adaptation is important for firms who need to be prepared and overcome crises that diffuse rapidly in an interconnected and global world, and for policy makers who seek to find remedies to a global crisis (Agarwal et al., 2009). This is critical for new firms, for two reasons. From a management perspective, new firms need to find rapid ways to adapt because of lack of internal slack resources, otherwise available to established firms as a buffer to external scarcity (Bradley et al., 2011b). From a policy perspective, new firms may need to be sheltered from a storm that undermines them too soon, before they can gain legitimacy and develop the complementary assets necessary to commercialise their innovative ideas (Gans and Stern, 2003). Appreciating how to shelter in the storm can help to maintain alive the entrepreneurial experimentation (Kerr et al., 2014; Rosenberg, 1992), which policy makers call upon to boost economic growth and recovery in times of crisis (Audretsch et al., 2007; Stern, 2006). Our results identify which innovative capabilities are crucial to building adaptive capabilities, necessary to overcome the crisis and to successfully recover after the recession. When resources at the macro level are scarce, understanding which firms have better chances to survive an environmental jolt can be useful to inform the choice of where to concentrate resources, instead of dispersing them among all.

\section{Background and hypotheses}

From an evolutionary perspective, organisational survival is the outcome of the processes of selection and learning, in an environment characterised by asymmetries in the distribution of heterogeneous resources endowments. This distribution will define the relative position of competing organisations along with some dimension of economic performance (e.g. productivity, profitability) or fitness (Nelson and Winter, 1982). The positional advantage 
that derives from the control of heterogeneous resources will shield an organisation from the process of natural selection, enhancing survival likelihood (Barnett et al., 1994). In this respect, the resource-based view (RBV) of the firm highlights that to produce a sustained competitive (i.e. positional) advantage, and therefore to survive in the long term, firms' resources need to be valuable, rare, imperfectly imitable, and not substitutable (Barney, 1991). While selection operates on existing asymmetries, over time, the relative positions of individual firms along the distribution of productivity or fitness levels change per effect of adaptation and learning (Nelson and Winter, 1982). Hence, survival likelihood is explained as the combined outcome of the intensity of market interactions, operating as a mechanism of natural selection, and the heterogeneous rates of firm learning (Dosi et al., 1995)

Consistent with an evolutionary perspective, innovation influences firm survival because innovative outcomes enhance the competitive position or fitness of firms (Banbury and Mitchell, 1995; Cefis and Marsili, 2012; Colombelli et al., 2016), while, conversely, innovative investments may impose greater risks and uncertainty in outcomes (Buddelmeyer et al., 2009; Fernandes and Paunov, 2015). There is evidence that having introduced an innovation enhances the probability of firm survival persistently over time, years after the innovation has taken place (Cefis and Marsili, 2006). Innovation is a valuable and appropriable resource that generates a sustained positional advantage for the firm in a competitive context (Barney, 1991). Innovation is also a capability because firms learn how to recognise and exploit commercially novel opportunities and how to solve problems, as they engage in the process of introducing novel products, processes or practices (Nelson and Winter, 1982). This cumulatively built knowledge, which includes skills, competences, and practices is stored in routines (Nelson and Winter, 1982) and generates persistence in innovative capabilities and outcomes (Cefis, 2003). Such a learning process enhances organisation flexibility and adaptability to future changes, either internal or external to the 
firm. Hence, innovation as a resource and a capability contributes to create both a 'positional advantage', because innovative firms are rewarded through market selection in view of asymmetries in some dimension of performance (or fitness), and an 'adaptive advantage', because firms with superior innovative capabilities can change their relative position in the distribution of performance, through learning and the exploration of new opportunities. While the overall importance of innovation for survival is well established in the literature, little is known about the distinctive contribution of positional and adaptive mechanisms of survival.

To isolate the above effects more clearly, we focus on the concept of innovative entrepreneurship, which can be defined as the intersection between the process of innovation and the process of organisational creation. Innovative entrepreneurship combines two sources of uncertainty: one associated with the partly random nature of the innovation process, which involves experimentation and learning by trial-and-error (Nelson and Winter, 1982), and the other associated with the process of creating new organisations when resources need to be leveraged in presence of information asymmetries (Amit et al., 1998) and lack of legitimacy (Aldrich and Fiol, 1994). These sources of uncertainty are mutually reinforcing in innovative new firms. Uncertainty and possible disagreement about the value of an innovative idea, due to its novelty, can amplify information asymmetries in the factors markets, between an entrepreneur and those who own or control resources, thus reinforcing uncertainty in the process of assembling resources for setting up a new firm (Dew et al., 2004). As a consequence, new companies seeking to innovate as they are created experience unique and more precarious challenges compared to established companies innovating on a routine basis (Winter, 1984). The situation of uncertainty on multiple levels, which innovative new firms are exposed to and handle at this early and critical stage of their life cycle, may not be dissimilar to the uncertainty caused by an external shock. Because learning takes place in similarly uncertain settings, it is plausible to assume that the experience of true uncertainty in 
one situation helps to build flexibility and adaptability to true uncertainty in another. On this basis, we assume that innovative capabilities, especially when developed early in the organisational life cycle, create adaptive capabilities to future shocks. Hence, our interest is in the innovative capabilities that new firms possess at the time of the founding, before the environmental jolt occurs, unconditionally on future changes in innovative investments and strategies, which they may introduce later on, or in response to the external shock (Amore, 2015; Archibugi et al., 2013). Accordingly, we choose to study cohorts of new firms created before the financial crisis of 2007-2008. For these firms, we first consider how the introduction of an innovation at founding influences their survival likelihood 'on average' over time. This 'average effect' indicates the existence of an underlying survival premium from an early innovation, across time periods. Hence, we state:

Hypothesis 1. Innovative capabilities at founding increase the survival likelihood of new firms, before, during and after an environmental jolt.

The financial crisis of 2007-2008 is an example of an environmental jolt and offers an experimental setting (Meyer, 1982), which can help to disentangle the positional and adaptive components in the effect of innovation on firm survival. For example, this approach relying on environmental jolts has been applied to study how resources ownership structure influences the firm's survival (Bradley et al., 2011a). Specifically, the differentials in survival likelihood before, during and after an environmental jolt are indicative of distinct positional and adaptive advantages. The underlying argument is that organisations taken by surprise by an environmental jolt need to learn fast, and the conditions that enable the flexibility and adaptability necessary for survival during and after the shock differ from the conditions sustaining a competitive advantage before the shock. 
We extend this line of reasoning to innovation as a resource and a capability of the firm. We begin with the consideration, in line with the argument made by Bradley et al. (2011a), that in the face of an environmental jolt, adaptive capabilities become imperative and more important than positional advantages. Earlier studies based on evidence preceding the financial crisis show that innovation enhances survival likelihood (Cefis and Marsili, 2012). On this basis, we assume that innovators benefit of a positional premium for survival in 'good times', under the ordered functioning of competitive forces and the selective pressure of a relatively predictable environment (before an environmental jolt occurs). We then propose that innovators also benefit from an additional adaptive premium for survival for the 'bad times' to come, when the selective pressure unexpectedly intensifies and the environment suddenly becomes extreme (during and after the environmental jolt).

The benefits of adaptive capabilities in the face of an environmental jolt are more substantial for new firms than for established firms. New firms are more likely to be in "clear and present danger' in times of crisis, because of their liabilities of newness and smallness, while their longer-lived counterparts enjoy a position of legitimacy and more affluent resources bases (Aldrich and Fiol, 1994). At the fundamental level, a financial crisis exacerbates the financial constraints new firms experience mostly when compared to established companies less reliant on external funds (Cowling et al., 2012).

Following the above line of reasoning, and having assumed, in Hypothesis 1, a general survival premium from innovation exists, we then focus on the 'differential effect' due to the occurrence of an external shock. We consider how the effect of having innovated or not at founding, on the survival likelihood of new firms, differs across the three time periods: before, during and after the shock. Specifically, we expect that starting an organisation with an innovation has a greater influence on survival during and after the financial crisis than it does before the crisis. Because observed in correspondence of an 
environmental jolt, we interpret such a differential effect before, during and after the jolt, as the expression of an adaptive survival premium, which adds to an underlying positional survival premium of innovative capabilities at founding. Hence, the following hypothesis. Hypothesis 2. The effect of innovative capabilities at founding is greater for the survival likelihood during and after an environmental jolt than for survival before the jolt.

Innovation takes place in different forms, and the influence of each form on survival can differ, being more or less consequential. In the literature on firm survival, there has been a focus on the implications of product and process innovations and the underlying $R \& D$ investments. It has also been shown that companies with capabilities in both process innovation and product innovation benefit of an additional premium for survival because of complementarities between different forms of innovation (Cefis and Marsili, 2005; 2012). Besides product and process innovations, also labelled as 'technological innovations' (Battisti and Stoneman, 2010), the field of innovation studies has increasingly dedicated attention to other forms of 'non-technological innovations' or managerial innovations (Mol and Birkinshaw, 2009). This approach attempts to gain a more comprehensive understanding of innovation, in services and in manufacturing, together with a more refined and systematic measurement of innovation in its multiple dimensions (Wengel et al., 2000). The category of non-technological or managerial innovations includes changes in organisational and marketing practices. Non-technological innovations and technological innovations are interrelated, especially in sectors like services (Tether and Tajar, 2008). As a result, introducing organisational and marketing innovations often occur in combination and in support to product and process innovations, enabling the exploitation of synergies and complementarities of some type (Battisti and Stoneman, 2010), with positive outcomes on the overall innovative performance of firms (Ballot et al., 2015; Schubert, 2010). Hence, it can be expected that both technological and non-technological innovations positively influence 
survival likelihood. It is possible, however, that the differential effect in times of crisis becomes more apparent and critical for technological innovations, because of their more fundamental role, as compared to non-technological innovations,

In fact, organisational and marketing innovations are viewed as less demanding or 'soft' because they involve relational rather than technological changes (Tether and Tajar, 2008). They play a role functional in support to the success and commercialisation of technological innovations (Schubert, 2010). Furthermore, performance's benefits from engaging in a variety of innovation forms at the same time may not be straightforward. For example, the pursuit of organisational innovation simultaneously to product and process innovations appears to reduce the benefits of complementarities between product and process innovation. Specifically, performing product and process innovations, without organisational innovation, is a better strategy than carrying out the three innovation forms concurrently (Ballot et al., 2015). Thus, the benefits of performing more than one form of innovation can be outbalanced by the costs and complexity of introducing multiple forms of innovation. At the same time, introducing only organisational innovations produces the lowest outcomes in terms of economic performance for the firm, as compared to any other possible combination of product, process and organisational innovations (Ballot et al., 2015). Overall, earlier studies indicate the existence of a hierarchical order among innovation forms, with managerial innovations having an ancillary role to technological innovations. Managerial innovations can support or complement product and process innovations, but appear to be less consequential on their own.

The hierarchical order in innovation forms may be even more stringent for new firms, which typically lack the resources and scale needed to deal with complex and diverse innovation projects (Nooteboom, 1994). The net effect between the benefits of multi-level innovations and the associated costs and complexity depends on contingent characteristics, in 
particular, on firm size (Ballot et al., 2015). These costs and complexity can be especially difficult to handle by financially constrained new firms in times of crisis. Because new firms can rely less on slack resources, as an essential buffering mechanism in times of crisis (Bradley et al., 2011b), they may be forced to restrict investments in potentially attractive projects (Campello et al., 2010). Hence, it is plausible that in the face of an environmental jolt, creating a hostile and extreme environment, adaptability and survival will ultimately depend on fundamental rather than ancillary capabilities. In sum, we assume that, consistent with Hypothesis 1, organisational and marketing innovative capabilities at founding increase the likelihood of survival on average over time. We also expect, however, that their differential effect during and after a crisis, as compared to before the crisis period, is smaller than the differential effect of capabilities in product and process innovations.

Hypothesis 3. During and after an environmental jolt, the effect of innovative capabilities at founding on the survival likelihood of new firms is greater for product and process innovations as compared to organisational and marketing innovations.

\section{Research Design}

\subsection{Data description and construction of the sample}

In Europe, the period of economic crisis that started in 2007 took a course that has seen distinct stages of decline and partial recovery, through the global financial crisis and the Eurozone debt crisis. To analyse how the conditions for the survival of new firms changed across the different stages of this long period of economic crisis, we identify three different time segments in our data: (i) the pre-crisis period from 2001 to 2006, (ii) the global financial crisis in 2007-2010, and (iii) the recovery period in 2011-2015. For the analysis, we employ several micro-datasets for companies operating in the Netherlands, collected and managed by the Netherlands Central Statistics Office (CBS). 
Sample. To construct our sample, we started by identifying the population of new firms over the period of interest, from the General Business Register (or ABR according to the Dutch initials). The ABR includes all the companies registered for fiscal reasons in the Netherlands and therefore offers a comprehensive list of the whole population of firms active in the country. For these firms, the ABR reports the date in the month a firm is first included in the register and the dates in which a firm experiences critical events changing its ownership structure. In the ABR, these events are identified by the type of change, whether it involves the creation of a new organisational form or the demise of an existing one. When an event occurs, it is thus possible to know both its typology and the date of occurrence. As events resulting in the entry of a new firm, we consider: greenfield birth; spin-off, entry due to the disintegration of an existing firm, merger, entry due to the restructuring of an existing firm. Using the date an event occurred, which lead to the first inclusion of a firm in the ABR, we can find the population of new firms in 2001-2006.

From this population of new firms from the ABR, we select those firms for which innovation data is available, over the same time period, from the Community Innovation Survey (CIS), to obtain information on their innovative capabilities at founding. This is possible by using three waves of the CIS: the CIS 3.5, CIS 4 and CIS 2006. Because each CIS survey provides innovation data over the three years preceding the year of the administration, we select the two most recent entry cohorts within the period covered by each survey. Accordingly, for the CIS 3.5 (covering data for 2000-2002) we choose the entry cohorts of 2001 and 2002, for the CIS 4 (2002-2004) the entry cohorts of 2003 and 2004, and for the CIS 2006 (2004-2006) the entry cohorts of 2005 and 2006. Because in the Netherlands the CIS was carried out every two years, instead of every four as in most EU countries, this timeframe enables us to have innovation data that fully cover the time of observation, from 2001 to 2006, and that are close to the year of firm creation, either in the 
same or one year after creation, for each entry cohort over such a time period. In other words, our sample includes new firms that could have been innovative from onset or could have become innovative within maximum two years from creation.

The CIS sample is a stratified random sample drawn from the ABR (the same dataset from which our population of new firms is selected) and is constructed to include firms with at least 10 employees. Because of our focus on new firms, the matching with the CIS sample implies that only new firms with at least 10 employees at the time of observation are included in the final sample. Hence, our final sample excludes new micro firms - as defined according to the classification of enterprises by the European Union Commission (2003) -, which did not demonstrate a high potential for future growth, in the first few years after creation. This final sample comprises 2329 new firms divided by year: 325 in 2001; 278 in 2002; 309 in 2003; 401 in 2004; 449 in 2005; and 667 in 2006 (Table 1a).

\subsection{Variables}

Our dependent variable is the hazard rate of exit. It defines the probability of exiting the market at a certain time, conditional on having survived until that time. For each new firm in the sample, the hazard rate is computed over the entire period from its entry in the register (the first date is January 2001) to December 2015, the last month of observation, based on the yearly files of the ABR, in 2001-2015. As events resulting in the exit of a firm, we consider: death, closure due to the disintegration of an existing firm, merger and acquisition (M\&A), and closure due to the restructuring of an existing firm.

To compare the hazard of the exit of innovative new firms to non-innovative new firms, we match the data from the ABR with the CIS, following each cohort of new firms entered the period before the financial crisis, 2001-2006. Specifically, for each entry cohort selected, the innovation data are gathered from the wave of the CIS that is the closest to cover either the same year or the year immediately after the company entry (see the previous 
paragraph for precise coupling). With this sequence of CIS waves and entry cohorts, we can obtain innovation data that do not overlap over time, while fully covering the time of interest.

To identify the introduction of different forms of innovation, we use a number of dummy variables based on the classification applied in the CIS questionnaire, which, in turns, adopts the OSLO Manual definitions of product innovation, process innovation, organisational innovation, and marketing innovation (OECD/Eurostat, 2005).

"A product innovation is the introduction of a good or service that is new or significantly improved with respect to its characteristics or intended uses. This includes significant improvements in technical specifications, components, and materials, incorporated software, user friendliness or other functional characteristics. " (OECD/Eurostat, 2005, 48)

"A process innovation is the implementation of a new or significantly improved production or delivery method. This includes significant changes in techniques, equipment and/or software." (OECD/Eurostat, 2005, 49)

"A marketing innovation is the implementation of a new marketing method involving significant changes in product design or packaging, product placement, product promotion or pricing. " (OECD/Eurostat, 2005, 49)

"An organisational innovation is the implementation of a new organisational method in the firm's business practices, workplace organisation or external relations." (OECD/Eurostat, 2005, 51)

Boundaries between the types of innovation are sometimes blurred, for example, there could be borderline cases between process innovation and organisational innovation, and some innovations may include elements of both types. Both process and organisational innovations aim at lowering costs by increasing efficiencies, which the former achieves through introducing new equipment and techniques, and the latter through new practices for 
organising people and work (OECD/Eurostat, 2005). Product innovation and marketing innovations share the purpose of increasing sales and market shares by better addressing the needs of existing customers or by opening new markets. These two types can coexist when existing products are significantly improved by product innovations that alter the functionality and use of the product, and of marketing innovations that modify the appearance, form or packaging (OECD/Eurostat, 2005). While different types of innovation are somewhat concurrent (as revealed by a certain covariance between the categories in Table 1b), we also want to explore to what extent each of them offers a distinct survival premium.

To account for the possible overlap between types of innovation and for the effects of each specific type, we define two alternative sets of dummy variables, which we enter one or the other at the time, but never simultaneously, into the model formulations. In one case, we consider a broadly defined 'Innovator' dummy variable which is equal to 1 if a firm has introduced at least one type of innovation and 0 if the firm has introduced no innovation (i.e. the firm is a non-innovator). In the other case, we define a set of four dummy variables, in which, for each type, the dummy variable is equal to 1 if the firm has introduced that particular type of innovation and equal to 0 otherwise (i.e. the firm is either a non-innovator or introduced other types of innovation than the one considered).

We include several control variables to account for heterogeneity in the likelihood of survival, by using data from the ABR. First, we control for firm-specific factors. A covariate of firm survival is the firm growth rate (Coad et al., 2013), which is calculated as the relative difference in the number of employees, as the measure of firm size, between the time of entry and the time of exit (or censoring). Differences in ownership status can also influence the decision to exit (Audretsch, 1994; Bradley et al., 2011a). Multi-unit firms are more likely to close a subsidiary or a branch than are independently owned firms to close down, because of lower costs of exit by multi-unit firms, who can redeploy the resources of the closed unit 
elsewhere within the organisation. Firms with recoverable capital costs are more likely to exit than firms with relatively sunk capital costs (Rosenbaum and Lamort, 1992). Furthermore, owners of independent enterprises are willing to accept lower rates of returns, and to keep their firm in the market even when underperforming, because of lower opportunity costs due to personal circumstance (e.g. lack of education, training and job alternatives), or because of strong personal attachment to the business (Audretsch, 1994; Gimeno et al., 1997). Hence, we introduce a dummy variable, group, which is set equal to 1 for all firms that, at the time of exit (or censoring), are subsidiaries of existing companies, and equal to 0 for those that are independently owned ${ }^{1}$. Second, we control for industry-specific conditions (Anderson and Tushman, 2001). In particular, we add the employment growth rate, computed by applying the indicator proposed by Haltiwanger et al. (2013), to measure job creation and job destruction, including the contribution of entries and exits, at various levels of aggregation. We calculate the Haltiwanger index over one year-time period as $g_{s t}=\left(E_{s t}-E_{s t-1}\right) /(0.5 *$ $\left.\left(E_{s t}+E_{s t-1}\right)\right) g_{j t}=\left(E_{s t}-E_{s t-1}\right) /\left(0.5 *\left(E_{s t}+E_{s t-1}\right)\right)$, where $E_{s t}$ is the number of employees in sector $s$ at time $t$ (Haltiwanger et al., 2013: 353). The sector $s$ is defined at the level of technological macro-sectors according to the Eurostat classification, which capture the influence of distinct technological regimes on firm survival (Audretsch, 1991). Also, we introduce a set of sectoral dummy variables that group firms into eight categories: agriculture, mining, manufacturing, energy, water management, knowledge-intensive services, less knowledge-intensive services, and other services. We exclude from the analysis the following sectors: construction, energy, and public administration because they are, respectively, too pro-cycle, too heterogeneous, and not constituted by private firms. Finally, we consider entry cohort-specific effects on firm survival, to account for heterogeneity in founding conditions common to all firms created in the same year, due to macroeconomic or 
industry-specific factors (Geroski et al., 2010). Hence, we enter the model cohort dummy variables per year of entry, from 2001 to 2006.

Table 1a reports the exit and survival rates of the six cohorts of new firms in our sample. Only one-third of the new firms survive at the end of our period of observation, spanning over 14 years. The average survival rate across entry cohorts is about $33 \%$, with a minimum of about $26 \%$ for the 2002 cohort, and a maximum of about $38 \%$ for the 2004 cohort. Table $1 \mathrm{~b}$ shows the descriptive statistics and the correlation matrix of the main variables of interest. It is worth noting that just above $53 \%$ of the new firms have introduced an innovation (of any type) at founding. The innovation most frequently introduced at founding is organisational innovation (38\%), while the marketing innovation is the least $(16 \%)$. Product and process innovations have been introduced respectively by $26 \%$ and $23 \%$ of the firms in our sample. In more detail, 602 firms have introduced a product innovation, and 533 a process innovation. Those firms that have introduced simultaneously both product and process innovations at their founding are 355, representing the $15 \%$ of the entire sample.

-- Insert Tables $1 a$ and $1 b$--

As for the correlation coefficients, there is, as expected, some degree of correlation between the various forms of innovations, because firms may pursue different types of innovation at the same time. Nevertheless, the maximum correlation coefficient for the variables that will enter simultaneously into the same model estimation is equal to 0.511 , for the combination of product and process innovations. This value is below conventional thresholds that would warrant concern for multicollinearity (Farrar and Glauber, 1967). The only coefficient above the 0.70 threshold of strong correlation is observed between 'Innovator' and 'Organisational innovator' $(r=0.729)$; these variables are never entered simultaneously in any model specification, because, by definition, the former is necessary for the latter. 


\subsection{Methodology}

In order to test our hypotheses, we implement a piece-wise exponential hazard model because we recognise that the 'macro' (or systemic) conditions for operating in the market are significantly different across the periods that lie within our observation period 2001-2015. The global financial crisis of 2007-2010 is an example of an environmental jolt and offers an experimental setting that can help to disentangle the positional and adaptive components in the effect of innovation on firm survival. Specifically, we examine the differential effects of the founding conditions of new firms, created in the six years preceding the onset of the financial crisis, on the hazard rates of exit observed before the crisis, which can be considered as the placebo effect (Aghion et al., 2017), during the crisis, and in the years following the crisis. These differences, in the conditions underlying firm survival over distinct time periods, are taken into consideration by modelling firms' survival according to a proportional hazard model, in which the baseline hazard rate is assumed to be constant within each time period, but with a value that differs across the time periods (Jenkins, 2005). Following Rodríguez (2013), let us consider a proportional hazard model of the form

$$
\lambda_{i}\left(t \mid \mathbf{x}_{i}\right)=\lambda_{0}(t) \exp \left\{\mathbf{x}_{\mathbf{i}}^{\prime} \boldsymbol{\beta}\right\}
$$

imposing mild assumptions on the baseline hazard $\lambda_{0}(t)$, namely that: (a) the overall time period of observation is subdivided into reasonable or appropriate intervals and (b) the baseline hazard is assumed to be constant in each interval. These assumptions lead to a piecewise exponential model, which constitutes a flexible or semi-parametric approach to fitting a survival model. This is intermediate between a parametric approach, in which a specific functional form is assumed for the baseline hazard, and a non-parametric approach, in which the baseline hazard is left entirely unspecified (Rodríguez, 2013).

The observation period is partitioned into $j$ intervals, with the $j-$ th interval defined as $\left[\tau_{j-1}, \tau_{j}\right)$, where $\tau$ is the time indicator. We choose our $j$-th intervals, with $\tau$ equal to 3 : 
"Time-period 1 (tp1)" for the pre-crisis period, from January 2001 to December 2006; "Timeperiod 2 (tp2)" for the crisis period, from January 2007 to December 2010; and "Time-period 3 (tp3)" for the recovery period, from January 2011 to December 2015.

The choice of $1^{\text {st }}$ Jan 2007 and $31^{\text {st }}$ December 2010, as appropriate cut-off points, is based on the Life Tables reported in Table 2 and on the hazard function for our sample in Figure 1. The Life Tables (columns "Exits t0-t1" and "Hazard" of the "All Exits" section of the Table) show distinctly that the number of exits during the period from 1 January 2007 to 31 December 2010 increases drastically (370 exits in 2007, 162 in 2008, 114 in 2009 and 306 in 2010) regarding the previous and the following period. Coherently, the hazard rate passes from about 0.04 (pre-crisis period) to 0.20 in 2007 arriving at 0.25 in 2010, to decrease again in the following years to levels around 0.07. If we graph the hazard function for our sample in Figure 1 (left-hand panel), these cut-off points isolate the peak of the hazard function at the centre from the left and the right sides, in which the function is markedly lower. These cutoff points are also visible in Figure 1 (right-hand panel), in correspondence to the two breaks of the cumulative hazard function, where the function changes slope. This plot also shows that, within the three identified intervals, the cumulative hazard function is approximated by a straight line, implying that the assumption of constant hazard rates within the selected time periods will not bias the survival estimates.

\section{-- Insert Table 2 and Figure 1 about here --}

Having selected the $j$ intervals, we then assume a constant baseline hazard, $\lambda_{j}$, within each interval, so that:

$$
\lambda_{0}(t)=\lambda_{j} \text { for } t \in\left[\tau_{j-1}, \tau_{j}\right)
$$

We can, therefore, model the baseline hazard using $\tau$ parameters $\lambda_{1}, \ldots, \lambda_{\tau}$. Each parameter represents the risk of the reference group inside a particular time period (Rodríguez, 2013). 
Given the formulation of the proportional hazard model in equation (1), we can rewrite the piece-wise exponential model as:

$$
\lambda_{i j}=\lambda_{j} \exp \left\{\mathrm{x}_{\mathrm{i}}^{\prime} \beta\right\}
$$

where $\lambda_{i j}$ is the hazard of subject $i$ in the time period $j, \lambda_{j}$ is the baseline hazard of such a time period, and $\exp \left\{\mathrm{x}_{i}^{\prime} \beta\right\}$ is the relative risk for the subject $i$, at any given time, compared to the baseline, for the covariates' values $\mathrm{x}_{\mathrm{i}}^{\prime}$. Taking the logs, it yields the additive log-linear model

$$
\log \lambda_{i j}=a_{j}+\mathrm{x}_{\mathrm{i}}^{\prime} \beta
$$

where $a_{j}=\log \lambda_{j}$. This is the standard $\log$-linear model, in which the time periods are considered as regressors. In our case, $a_{j}$ is equal to "Time-period 1 (tp1)" for the pre-crisis period, "Time-period 2 (tp2)" for the crisis period, and "Time-period $3(\operatorname{tp} 3)$ " for the recovery period.

To test our hypothesis of a differential effect of founding conditions due to a firm's response to the occurrence of an environmental jolt, and thus indicative of organisational adaptive capabilities, we estimate two sets of models with standard errors clustered by firm. In the first set (Tables 3a and 3b, from Model 1 to Model 6), we assume that the constant baseline hazard is different across the three time periods while the effects of all the covariates are independent of the time period. In this case, the three time-periods are regressors in the model: their estimated coefficients represent the effects of different time periods on the (unknown) baseline hazard. Conversely, the estimated coefficients of all the other variables are 'on-average' effects throughout the entire period of observation, i.e. across the three timeperiods. In the second set of models (Tables 4a and 4b, from Model 7 to Model 13), besides assuming that the constant baseline hazard differs across time-periods as above, we also allow for the effects of our explanatory variables to vary by the time period. Hence, we add to the model the interactions between the variables of interest and each time period. Here, the 
estimated coefficients report the effect of a specific variable in a specific time period on the hazard rate, distinguishing different effects of the same variable across different time-periods.

\section{Results}

\subsection{Univariate Analysis}

Figure 2 reports the survival functions for each entry cohort, estimated separately using the Kaplan-Meier estimator. This is a non-parametric estimator of the survival function, also known as the product-limit estimator, and it considers right-censored observations, as in our case.

-- Insert Figure 2 about here --

In Figure 2, the estimated survival rates are reported by year, as on the $x$-axis, and for this reason, the plots appear as step-functions with discontinuities, dropping when the total number of failures is observed per year. In all the plots, the survival function displays two more marked drops consistent with our assumption of differential survival conditions over the three time periods. Regardless of the cohort, the survival functions show that after 10-15 years from start (depending on which cohort), approximately $25 \%-30 \%$ of the starting cohort of firms survives, with a survival rate that seems to stabilise 10 years after entry. In other words, 1 out of 3 , in the most resilient cohorts, or 1 out of 4 , in the others, of our highpotential new firms survive after 10 years. Usually, economic and policy institutions at different level identify these firms as an important driver for economic growth, especially during recession times. Consequently, it could be useful to know which ones are more likely to survive an environmental jolt.

\subsection{Multivariate analysis}

Table $3 \mathrm{a}$ and $4 \mathrm{a}$ report the estimated coefficients (and clustered standard errors) of the piecewise exponential hazard models, over the period from 2001 to 2015 . We start with a 
comparison of the coefficients of the time dummies identifying the three time periods of interest, before, during, and after the 2007-2008 crisis. The estimates of the effects of the time periods on the hazard rate or (conditional) failure rate $^{2}$ are consistent throughout all the model specifications in significance, sign, and magnitude. The coefficients are all negative and statistically significant $(\mathrm{p}<0.01)$, ranging from -3.638 to -3.412 for the pre-crisis period (Time-period 1), from -2.211 to -2.338 for the crisis period (Time-period 2) and from -3.113 to -2.986 in the post-crisis period (Time-period 3). Thus, the hazard rate is closest to the baseline hazard in the crisis period, it drops somewhat in the post-crisis period, and it falls to the lowest level in the pre-crisis period. Hence, the survival chances are most favourable before the crisis, worsen during the crisis, and partially recover after the crisis, without nevertheless returning to the pre-crisis values. This pattern confirms our basic assumption that the 2007-2008 financial crisis has been actually an environmental jolt which firms had to face in order to survive.

Our first interest is in establishing the influence on the survival likelihood of innovative capabilities at founding (Hypothesis 1), defined broadly as the ability to innovate, and thus encompassing the ability to innovate by specific forms of innovation. Table $3 \mathrm{a}$ reports the estimates for various specifications of the model, in which the independent variables are not interacted with the time regressors. This formulation implies that the effects of the independent variables are averaged across the three periods (before, during and after the crisis) and provides the indication of the positional survival premium which can be attributed to the ability of a new firm to innovate at founding. This is the premium given by innovation at the time of the founding regardless of the specific context or moment in time for survival.

-- Insert Table 3 a about here -- 
The estimates of the innovator dummy in Model (1) in Table 3a show that innovative new firms created before the financial crisis experienced lower hazard rates of exit than noninnovative new firms, on average across the three time periods. In Models (2) and (3), which include each type of technological innovation separately, the effect of lowering the hazard rate is slightly higher for product innovation $(\beta=-0.231, \mathrm{p}<0.01)$ than for process innovation $(\beta=-0.205, p<0.01)$. The coefficients remain negative and statistically significant, when entering both types of innovation into the same model formulation in Model (4), as well, with a slightly greater effect for product innovation $(\beta=-0.175, \mathrm{p}<0.05)$ than process innovation $(\beta=-0.123, p<0.10){ }^{3}$ Thus, we find that the capability to introduce technological innovations at founding lower the exit rate years after entry, with a somewhat greater role for capabilities in product innovation than in process innovation.

We then evaluate the influence of managerial innovations by adding organisational innovation in Model (5), and marketing innovation in Model (6), which is also the complete model with all four types of innovation. In both models, the coefficient for organisational innovations is not statistically significant. Somewhat surprisingly, in Model (6), the effect of marketing innovation is to increase the hazard rate of exit for new firms, although with a marginally statistically significant coefficient $(\beta=0.126, p<0.10)$. In this most comprehensive formulation, the strongest effect is observed for product innovation $(\beta=-$ 0.197, $\mathrm{p}<0.01)$, and somewhat lower for process innovation $(\beta=-0.123, \mathrm{p}<0.10)$. In sum, innovative capabilities, as broadly defined by the 'innovator' dummy variable, have a positive and long-lasting effect on the survival likelihood of firms, years after they have been created, consistent with Hypothesis 1. The survival time ranges from a minimum value of one year after funding, to 14 years after founding (for a firm created in 2001 and surviving until 2015). As a necessary condition for Hypothesis 1, one would also expect that the same relationship holds for each type of innovation. In contrast, we observe 
notable differences when separating product, process, organisational and marketing innovations. While capabilities in product and process innovation increase the survival likelihood of new firms consistent with Hypothesis 1, innovative capabilities in marketing lower survival, contrary to the hypothesis. Innovative capabilities in organisational practices do not significantly alter the chances of survival, on average over time. Because the effect on survival varies in sign by type of innovation, our results only partly support Hypothesis 1.

\section{-- Insert Table $3 b$ about here --}

In order to rapidly evaluate the effects sizes of the relationships described above, Table $3 b$ reports the hazard ratios, equal to $\exp (\beta)$, for the main effects of interest in the estimated models. Focusing on the statistically significant effects only, and starting with the most comprehensive definition of innovation (Model 1), we observe that innovative new firms experience hazard rates $17.1 \%$ lower than non-innovative new firms, on overage over the three time periods (the hazard ratio is below 1). When distinguishing the innovations types in the complete model (Model 6), the hazard rate of exit is $17.9 \%$ lower for product innovation, $11.6 \%$ lower for process innovation, and $13.4 \%$ higher for marketing innovation (the hazard ratio is above 1$)$.

The previous results refer to the average effects of the explanatory variables across the three time periods of interest. In this formulation, each time period has an effect on the intercept of the model by differentiating the baseline hazard rate but does not change the coefficients of the explanatory variables. The next step is to allow those coefficients to vary with the time periods as the variation would reflect how the financial crisis affects the relationship between survival and innovative capabilities (Hypotheses 2 and 3). For this purpose, Table 4a reports the estimates of the model which includes the interaction terms between the innovation variables and the dichotomic variables corresponding to the three time periods. The interaction terms bring to light how the effects of innovation at founding 
vary over time, before the crisis, during the crisis, and in the recovery stage. The comparison in the interaction terms estimated during and after the crisis period gives, regarding the period preceding the crisis, provides an indication of the existence of an adaptive survival premium given by innovation to firms that have innovated at their founding. When estimated during and after the crisis, the interaction coefficients reflect the combination of an adaptive and a positional component which we are not able to disentangle entirely, since we cannot establish what would have happened without the crisis. Nevertheless, observing an effect during and after a crisis, which is not present before the crisis reveals the existence of this adaptive premium.

-- Insert Table 4a about here --

Model (7) shows the effect of being an innovator at founding, independent of the type of innovation when the effect is differentiated over the three periods. Here we observe that the coefficient of the interaction term between the Innovator variable and the time period is negative and statistically significant, lowering the hazard rate of exit, during the shock (time period 2), while it is not statistically significant before the shock (time period 1) and after the shock (time period 3).

To better qualify the previous result in which the coefficient of the Innovator variable reflects the combined effect of different types of innovation, we distinguish the model formulation by type of innovation (Models 8 to 13). Starting with technological innovations, in Model (8), we find that introducing product innovation at founding lowers the hazard rate of exit during the crisis $(\beta=-0.332, \mathrm{p}<0.01)$, as well in the recovery period, although with lower statistical significance $(\beta=-0.230, \mathrm{p}<0.10)$. In Model (9), introducing process innovation lowers the hazard rate only during the crisis $(\beta=-0.420, \mathrm{p}<0.01)$ with no statistically significant effects on the other time periods. Interestingly, when the two types of technological innovations are entered simultaneously in the equation (Model 10), the above 
coefficients remain statistically significant, and the effect of product innovation becomes more important over time, as the reduction in hazard rates is stronger in the recovery period $(\beta=-0.358, \mathrm{p}<0.05)$ than during the crisis $(\beta=-0.180, \mathrm{p}<0.05)$. Conversely, process innovation lowers the hazard rate even more notably than product innovation during the crisis $(\beta=-0.338, p<0.01)$, but the effect is short-lived, as the estimated coefficient is not statistically significant in the stage of recovery. Moving to non-technological innovation, in Model (11), we observe that, as expected, organisational innovation lowers the hazard rates during the crisis $(\beta=-0.261, \mathrm{p}<0.01)$, but, surprisingly, it increases the hazard rates in the period before the crisis $(\beta=0.294, \mathrm{p}<0.01)$. Finally, in Model (12), for marketing innovation, we find none statistically significant effect on the hazard rate, in any of the three time periods, when the variable is entered separately.

The above pattern remains broadly consistent when all the innovation forms are included simultaneously and interacted with the time regressors, in the complete Model (13). This formulation accounts for the fact that firms may introduce combinations of multiple forms of innovation at once. All the coefficients that were statistically significant in the previous models for product and process innovation (Model 10) and for organisational innovation (Model 11) maintain the same sign, statistical significance, and approximately the same value, in the complete model (Model 13). The only exception is the effect of marketing innovation at founding. While its coefficient is not statistically significant when considered separately from other innovation types (Model 12), it becomes statistically significant, with a positive sign for the time period 2 , in the complete model, indicating that the capabilities of new firms in marketing innovation increase the hazard rate in times of crisis $(\beta=0.232$, $\mathrm{p}<0.05)$ 
In order to assess effect sizes, Table $4 \mathrm{~b}$ reports the hazard ratios for the interaction terms with the main variables of interest. Focusing only on the statistically significant effects, we observe, that, for the most comprehensive definition of innovative capabilities (Model 7), being an innovator at founding lowers the hazard of exit of about $29 \%$ during the financial crisis, compared to an average reduction of $17.1 \%$ throughout the period of observation, from 2001 to 2015 (Table 3b). When accounting for the different types of innovative capabilities in the complete model (Model 13), we observe that the hazard of exit, during the financial crisis, is $18.3 \%$ lower for new firms that introduced product innovation at founding, $26.5 \%$ lower if they introduced process innovation, $18.3 \%$ lower for organisational innovators, and $26.1 \%$ higher for marketing innovators. As for the recovery period, product innovation is the only type of innovation with a statistically significant effect, lowering the hazard of the exit of about $28 \%$. Before the crisis, the hazard rate is only affected by capabilities in organisational innovation, with a value that is $31 \%$ higher for innovators.

Overall, the findings show that product innovation capabilities at founding have the most enduring effect in favouring the survival of new firms during and after an environmental jolt. Process innovation capabilities have a similar effect but only during and not after the jolt. Organisational innovation capabilities have a more complex effect: they increase survival during an environmental jolt only for the new firms that overcome the early risks of exit associated with this type of innovation. Marketing innovation capabilities even lower the likelihood of survival during the jolt. It is important to note that all these early innovative capabilities, with the only exception of organisational innovation, which even increases the early risk of exit, do not appear to affect the survival of new firms in the years that go from their entry to the onset of the financial crisis. Thus, the positive effect on the survival of innovation at founding is not clear at the early stage of the life cycle, and it becomes manifest only during the crisis, consistent with Hypothesis 2. Also, the evidence 
supports our Hypothesis 3 that technological innovations at founding generate stronger adaptive capabilities than non-technological innovations. While the former types have the effect of consistently increasing survival, the latter types exert a differentiated or even a detrimental effect on survival.

As for the control variables, we observe a negative and statistically significant coefficient of firms' growth rate (with $\mathrm{p}<0.01$ ) across all the model specifications (Table $3 \mathrm{a}$ and 4a) consistent with earlier findings (Coad et al., 2013). The estimated coefficient for the variable group is positive and statistically significant (with $\mathrm{p}<0.01$ ) with a magnitude relatively invariant across all the versions of the model. Hence, new firms that are subsidiaries of established companies at the moment of the exit, when deciding to exit, display higher hazard rates than independent new firms. This confirms earlier evidence (Audretsch, 1994) suggesting that the costs of exit are lower for subsidiaries than for independent new firms. A parent company can more easily close a subsidiary because it can redeploy resources (employees, equipment etc.) within the organisation. In contrast, the personal attachment of entrepreneurs to their own company or the absence of alternative job opportunities increase opportunity costs, so entrepreneurs may postpone the decision to close a business even when this is performing poorly (Gimeno et al., 1997).

\subsection{Sensitivity analysis}

We perform a sensitivity analysis to check whether the decision to consider the different types of exit as a single one may, in some ways, bias our results. In particular, we check whether including the exit by M\&A in the general definition of exit implies that we do not take into consideration the different meaning that exiting by M\&A might have in contrast to exiting by closure. Therefore, we estimate all the previous models considering M\&A as the only type of exit. Technically, this means that M\&As are identified as the only cause of 'failure' while the other types of exit are considered as 'exits' from the sample observation. 
This approach has the advantage of calculating the hazard rate with respect to a reference group that maintains the same numerosity as the reference group used to estimate the hazard rate in the original model specifications, as in the previous section, thus allowing for comparison among the results. Table 5 reports the average effects of innovation on the hazard rate. The results are much in line with the one obtained considering all types of exit altogether (Table 3a), giving support to our decision to consider M\&A similar to the other exits. The only substantial difference is the size of the innovation variables coefficients which is about two times the size of the same coefficients when considering all the exits together. In general, we can say innovation reduced the hazard rate of exit by M\&A.

-- Insert Table 5 and 6 about here --

Table 6 analyses the differential effects of innovation variables in the three-time periods considered. The two most important results are that product innovations strongly reduce the hazard rate during and after the crisis (as in Table 4a), while process innovation is only statistically significant in the period of recovery. It is worth noting that the magnitude of the product innovation coefficients is about 3 times larger than the ones estimated in Table 4a. Again these results support our decision to consider M\&A together with the other exits. However, if we consider earlier analysis conducted on different exit forms and the innovative capabilities of firms in the Netherlands during 'good times', in the period 1996 - 2003 (Cefis and Marsili, 2011; 2012), it is striking the difference we can notice among the effects of innovation on the probability of exit by M\&A. In fact, during a period characterised by economic stability (or better, by the absence of an exogenous crisis), product innovations enhance firms' exit by M\&A, suggesting that acquisitions can be a 'positive' form of exit. One possible interpretation, supported by the statistics shown in the Life Tables (Table 2; Column "Acquisition") is that, during the crisis, selling a firm was not a synonymous for cashing out and harvesting the entrepreneurial profits of having founded and developed an 
innovative firm, but, on the contrary, it was a way to avoid failure due to the crisis. In fact, the Life Tables show that most M\&As happened in a wave during the year 2010, in which 227 M\&As were concluded against 79 in 2007 at the beginning of the crisis, and less than 45 in all other years). These figures could suggest that some new firms, which tried hard to overcome the crisis, were not able to survive long enough, also because in Europe the crisis prolonged until later with respect to the United States. Ultimately, they were 'forced' to sell out and exit the market by an acquisition.

\section{Conclusions and Discussion}

In this study, we examine how founding innovative capabilities of new firms created in the six years preceding the onset of the global financial crisis of 2007-2008 influence their likelihood of survival. In particular, we are interested in the existence of the differential effects of the same founding conditions: when the effects are observed before the crisis, as placebo effects (Aghion et al., 2017) during the crisis, when adaptive capabilities become essential, and in the years following the crisis, when adaptive capabilities can also help recovery. Our results show that there are differential effects across the time periods and by type of innovative capabilities. Specifically, we find that, while introducing product and process innovation at founding do not affect the likelihood of survival in the years that span from firm creation to the onset of the financial crisis, those same innovative capabilities help firms to survive during the crisis. We interpret this differential as indicative of the emergence of adaptive capabilities to environmental jolts that stem from innovative capabilities developed at the early stage of a firm's life cycle. Capabilities in product innovations result especially important, as their differential effect on survival prolongs also to the period of recovery from the crisis. Conversely, introducing organisational innovations at founding displays a more differentiated effect. It influences survival both before and during the financial crisis, but with opposite sign effect, positive (increasing the hazard of exit) before 
the crisis and negative (reducing the hazard of exit) after the crisis. Hence, while early capabilities in organisational innovation can lead to adaptive capabilities to an external shock, this only happens for firms that have overcome the increased risk of exit that is associated with far-reaching and complex changes involving organisational practices and structures, when the organisation is still young. Finally, marketing innovation capabilities at founding do not generate adaptive capabilities to an environmental jolt, but, instead, they exacerbate the risk of exit during the jolt.

Our first conclusion is that innovative capabilities at founding act as adaptive capabilities. Innovative capabilities that emerge early in the life cycle of firms, when they face the uncertainty of building a new organisation, while also innovating, equip them with a survival premium when they need to deal with sudden changes in the environment, years later. Innovative capabilities at founding increase resilience in the face of an environmental jolt and, sometimes, during recovery. By highlighting how founding conditions imprint organisational adaption to (future) changes in the environment, our results confirm and qualify the role of founding conditions as 'markers' for the survival of new firms (Geroski et al., 2010). We show that the specific conditions in which new firms are created, in good times, continue to shape later on, in bad times, those heterogeneous capabilities they draw upon to respond to an external shock, like the financial crisis (Agarwal et al., 2009).

Second, our findings suggest that not all innovative capabilities are adaptive capabilities, but this depends on the form of innovation. In fact, early capabilities in marketing innovation are associated with greater risks of failure during an environmental jolt. The ability to change marketing practices and relationships with customers can occur to be even detrimental for survival to an external shock driven by demand. When demand for existing products is falling rapidly and dramatically, recurring to changes in the way firms approach customers in their current market may provide little benefit. In this context, 
investments in marketing strategies may add non-essential costs to already financially constrained firms and enhance risks. Conversely, our study would suggest that it is the ability to create and exploit new market opportunities, and potentially to attract new customers, through product innovations that can help firms to overcome a demand shock. As for other forms, such as organisational innovations, these appear to be too risky for newly created firms. Only once new firms have been in the market long enough, overcoming early liabilities, capabilities in organisational innovation can help them to be more resilient and adapt to sudden changes in the environment. We also find evidence that capabilities in product and process innovations entail superior adaptive capabilities than those in marketing and organisational innovations. This result is consistent with the notion that the performance effects of managerial (or non-technological) innovations may not be as strong and direct as those of technological innovations (Ballot et al., 2015).

Finally, our results indicate that adaptive capabilities have a different reach over time. In fact, among all innovation forms at the time of the founding, only the introduction of product innovations increases the likelihood of survival in the long run, extending over the period of (tentative) recovery from the crisis. Even more so, its effect strengthens over time, from the crisis to its aftermath. This pattern confirms and qualifies the role of entrepreneurial experimentation for economic growth and prosperity (Stern, 2006). It proves that recovery from a shock, such as the financial crisis, depends on the resilience of entrepreneurial firms, which early in life develop capabilities in product innovations focusing on experimentation. Conversely, relying on efficiency and cost-saving improvements (product innovation) or on changes in managerial practices (organisational innovation) can help young firms to survive the onset of a financial crisis, but does not sustain their survival in the longer term.

Our study presents some limitations. First, it focuses on a specific type of adaptive capabilities, which are the innovative capabilities of new firms in the first or second year of 
life, without considering innovations that could be introduced later on by the same firms, and in response to the financial crisis (Amore, 2015; Archibugi et al., 2013). Our goal was to show how organisational adaptation is shaped by capabilities imprinted early in a firm's life cycle, without possible sources of sample attrition in the analysis. Taking this into account, our study could be extended by incorporating changes in adaptive capabilities, which originate from the innovative investments and activities companies undertake during and after the crisis. Second, we assume that observing a differential effect of founding conditions, between the pre-crisis period and the crisis period, is equivalent to observe an additional 'adaptive survival premium' to an underlying 'positional survival premium'. Our goal was to show how an external shock can elicit certain types of adaptive capabilities, which are critical for survival in bad times, in addition to the positional advantage already manifest in good times. As for the measurement of the specific effects sizes, during the crisis, we can, however, only observe the total effect size, because the adaptive component is superimposed to the positional component of the premium. It would then be valuable to extend our model with proxies that measure the 'positional advantage' of a firm, in terms of its technological and market leadership, as distinct from its 'adaptive advantage', in terms of organisational flexibility and responsiveness acquired by each firm, in each period, and coming from their innovative activities. Including in the model the effects of distinct forms of innovative activities and outcomes, as they occur over time and not only at founding, can help to disentangle these specific advantages in each period. Thus, an interesting direction of further research would be to study new firm survival in conjunction with the persistence of innovation (Cefis, 2003; Cerulli and Potì, 2013)

From a policy perspective, the most worrying threat of a financial crisis is to halt that process of entrepreneurial experimentation, which is essential to promote economic growth and to boost the system out of a recession (Audretsch et al., 2007). As earlier studies reveal, 
the global financial crisis has caused firms to shrink their overall investments in innovation (Archibugi et al., 2013), to stop ongoing innovation projects (Paunov, 2012), and to revise their plans for technology spending (Campello et al., 2010). Our results are important in light of this evidence and policy concerns. Policy interventions aimed at actively encouraging corporate investments in innovation, to sustain entrepreneurial experimentation, are costly and uncertain in outcomes. Our results point out that firms with innovative capabilities at the start are able to navigate the crisis more successfully and can compete persistently in the phase of recovery, and this outcome is unconditional on their investment decisions during and after the crisis. Furthermore, our results identify the type of innovative capabilities that are most effective for building the adaptive capabilities necessary to overcome and pull out of the crisis. Yet, new firms that do have these necessary adaptive capabilities are also fragile in the face of a financial crisis, because of the liabilities of newness and smallness undermining survival in the aftermath of a sudden and disruptive shock. The challenge for policies aimed at supporting entrepreneurship, as a driver for economic recovery and growth, is to select the high potential firms which can provide a greater contribution, separating them from other 'marginal' entrepreneurial firms (Nightingale and Coad, 2014). Our study focuses on a set of new firms that have already overcome early liabilities and reached a non-marginal level of employment. Our results demonstrate that, for this set of firms, founding conditions can lower the information asymmetry surrounding the policy maker's choice of whom to fund (Hall, 2002), by signalling the firm long-term resilience and ability to adapt. This signal is especially clear and discernible for new firms that start with innovative product ideas. A policy approach that shelters these firms from the storm of a financial crisis could help to maintain alive the process of entrepreneurial experimentation during the crisis and to boost economic recovery, without dispersing precious resources. 


\section{References}

Agarwal, R., J. B. Barney, N. J. Foss and P. G. Klein (2009), 'Heterogeneous resources and the financial crisis: implications of strategic management theory', Strategic Organization, 7 (4), 467-484.

Aghion, P., N. Bloom, B. Lucking, R. Sadun and J. Van Reenen (2017), 'Turbulence, firm decentralization and growth in bad times', National Bureau of Economic Research, No. w23354.

Aldrich, H. and C. Fiol (1994), 'Fools rush in? The institutional context of industry creation', Academy of management review, 19 (4), 645-670.

Alfaro, L. and M. X. Chen (2012), 'Surviving the global financial crisis: foreign ownership and establishment performance', American Economic Journal: Economic Policy, 4 (3), 30-55.

Amit, R., J. Brander and C. Zott (1998), 'Why do venture capital firms exist? theory and Canadian evidence', Journal of Business Venturing, 13 (6), 441-466.

Amore, M. (2015), 'Companies learning to innovate in recessions', Research Policy, 44 (8), 1574-1583.

Anderson, P. and M. L. Tushman (2001), 'Organizational environments and industry exit: The effects of uncertainty, munificence and complexity', Industrial and Corporate Change, 10 (3), 675-711.

Archibugi, D., A. Filippetti and F.-M. Policy (2013), 'Economic crisis and innovation: Is destruction prevailing over accumulation?', Research Policy, 42, 303-314.

Audretsch, D. B. (1991), 'New-firm survival and the technological regime', The Review of Economics and Statistics, 441-450.

Audretsch, D. B. (1994), 'Business survival and the decision to exit', Journal of the Economics of Business, 1 (1), 125-137.

Audretsch, D. B., I. Grilo and A. R. Thurik (2007), 'Explaining entrepreneurship and the role of policy: a framework', Edward Elgar Publishing, 1-17.

Augier, M. and D. J. Teece (2009), 'Dynamic Capabilities and the Role of Managers in Business Strategy and Economic Performance', Organization Science, 20 (2), 410-421.

Ballot, G., F. Fakhfakh, F. Galia and A. Salter (2015), 'The fateful triangle:

Complementarities in performance between product, process and organizational innovation in France and the UK', Research Policy, 44 (1), 217-232.

Banbury, C. M. and W. Mitchell (1995), 'The effect of introducing important incremental innovations on market share and business survival', Strategic Management Journal, 16 (S1), 161-182.

Barnett, W. P., H. R. Greve and D. Y. Park (1994), 'An Evolutionary Model of Organizational Performance', Strategic Management Journal, 15 (S1), 11-28. 
Barney, J. (1991), 'Firm resources and sustained competitive advantage', Journal of Management, 17 (1), 99-120.

Battisti, G. and P. Stoneman (2010), 'How Innovative are UK Firms? Evidence from the Fourth UK Community Innovation Survey on Synergies between Technological and Organizational Innovations', British Journal of Management, 21 (1), 187-206.

Bradley, S. W., H. Aldrich, D. A. Shepherd and J. Wiklund (2011a), 'Resources, environmental change, and survival: asymmetric paths of young independent and subsidiary organizations', Strategic Management Journal, 32 (5), 486-509.

Bradley, S. W., D. A. Shepherd and J. Wiklund (2011b), 'The Importance of Slack for New Organizations Facing 'Tough' Environments', Journal of Management Studies, 48 (5), 10711097.

Buddelmeyer, H., P. H. Jensen and E. Webster (2009), 'Innovation and the determinants of company survival', Oxford Economic Papers, 62 (2), 261-285.

Campello, M., J. R. Graham and C. R. Harvey (2010), 'The real effects of financial constraints: Evidence from a financial crisis', Journal of Financial Economics, 97 (3), 470487.

Cefis, E. (2003), 'Is there persistence in innovative activities?', International Journal of Industrial Organization, 21 (4), 489-515.

Cefis, E. and O. Marsili (2005), 'A matter of life and death: innovation and firm survival', Industrial and Corporate Change, 14 (6), 1167-1192.

Cefis, E. and O. Marsili (2006), 'Survivor: The role of innovation in firms' survival', Research Policy, 35 (5), 626-641.

Cefis, E. and O. Marsili (2011), 'Born to flip. Exit decisions of entrepreneurial firms in hightech and low-tech industries', Journal of Evolutionary Economics, 21 (3), 473-498.

Cefis, E. and O. Marsili (2012), 'Going, going, gone. Exit forms and the innovative capabilities of firms', Research Policy, 41 (5), 795-807.

Cerulli, G. and B. Potì (2013), 'On Profit Differentials Between Persistent and Occasional Innovators: New Evidences from a Random-Coefficient Treatment Model', Long Term Economic Development, Springer: 363-393.

Clarke, G., R. Cull and G. Kisunko (2012), 'External finance and firm survival in the aftermath of the crisis: Evidence from Eastern Europe and Central Asia', Journal of Comparative Economics, 40 (3), 372-392.

Coad, A., J. Frankish, R. G. Roberts and D. J. Storey (2013), 'Growth paths and survival chances: An application of Gambler's Ruin theory', Journal of Business Venturing, 28 (5), 615-632.

Colombelli, A., J. Krafft and M. Vivarelli (2016), 'To be born is not enough: the key role of innovative start-ups', Small Business Economics, 47 (2), 277-291. 
Commission, E. U. (2003), 'Commission recommendation of 6 May 2003 concerning the definition of micro, small and medium-sized enterprises': 36-41.

Cowling, M., W. Liu and A. Ledger (2012), 'Small business financing in the UK before and during the current financial crisis', International Small Business Journal, 30 (7), 778-800.

Dew, N., S. R. Velamuri and S. Venkataraman (2004), 'Dispersed knowledge and an entrepreneurial theory of the firm', Journal of Business Venturing, 19 (5), 659-679.

Dosi, G., O. Marsili, L. Orsenigo and R. Salvatore (1995), 'Learning, market selection and the evolution of industrial structures', Small Business Economics, 7 (6), 411-436.

Farrar, D. E. and R. R. Glauber (1967), 'Multicollinearity in regression analysis: the problem revisited', The Review of Economic and Statistics.

Fernandes, A. M. and C. Paunov (2015), 'The Risks of Innovation: Are Innovating Firms Less Likely to Die?', Review of Economics and Statistics, 97 (3), 638-653.

Gans, J. S. and S. Stern (2003), 'The product market and the market for "ideas": commercialization strategies for technology entrepreneurs', Research Policy, 32 (2), 333-350.

Geroski, P. A., J. Mata and P. Portugal (2010), 'Founding conditions and the survival of new firms', Strategic Management Journal, 31 (5), 510-529.

Gimeno, J., T. B. Folta, A. C. Cooper and C. Y. Woo (1997), 'Survival of the Fittest? Entrepreneurial Human Capital and the Persistence of Underperforming Firms', Administrative Science Quarterly, 42 (4), 750.

Grewal, R. and P. Tansuhaj (2001), 'Building organizational capabilities for managing economic crisis: The role of market orientation and strategic flexibility', Journal of marketing, 65 (April), 67-80.

Hall, B. H. (2002), 'The financing of research and development', Oxford review of economic policy, 18 (1), 35-51.

Haltiwanger, J., R. S. Jarmin and M.-J. of and (2013), 'Who creates jobs? Small versus large versus young', Review of Economics and Statistics, 95 (2), 347-361.

Jenkins, S. P. (2005), 'Survival analysis', Unpublished manuscript, Institute for Social and Economic Research, University of Essex, Colchester, UK.

Kerr, W. R., R. Nanda and M. Rhodes-Kropf (2014), 'Entrepreneurship as Experimentation', Journal of Economic Perspectives, 28 (3), 25-48.

Lins, K. V., P. Volpin and H. F. Wagner (2013), 'Does Family Control Matter? International Evidence from the 2008-2009 Financial Crisis', Review of Financial Studies, 26 (10), 25832619.

Makkonen, H., M. Pohjola, R. Olkkonen and A. Koponen (2014), 'Dynamic capabilities and firm performance in a financial crisis', Journal of Business Research, 67 (1), 2707-2719. 
Meyer, A. D. (1982), 'Adapting to environmental jolts', Administrative Science Quarterly, 27, 515-537.

Mol, M. J. and J. Birkinshaw (2009), 'The sources of management innovation: When firms introduce new management practices', Journal of Business Research, 62 (12), 1269-1280.

Nelson, R. R. and S. G. Winter (1982), An evolutionary theory of economic change, Harvard university press.

Nightingale, P. and A. Coad (2014), 'Muppets and gazelles: political and methodological biases in entrepreneurship research', Industrial and Corporate Change, 23 (1), 113-143.

Nooteboom, B. (1994), 'Innovation and diffusion in small firms: theory and evidence', Small Business Economics, 6 (5), 327-347.

OECD/Eurostat (2005), Oslo Manual, OECD Publishing.

Paunov, C. (2012), 'The global crisis and firms' investments in innovation', Research Policy, 41, 24-35.

Rodríguez, G. (2013), 'Lecture notes in Generalized Linear Models', Lecture notes in Generalized Linear Models.

Rosenbaum, D. I. and F. Lamort (1992), 'Entry, barriers, exit, and sunk costs: an analysis', Applied Economics, 24, 297-304.

Rosenberg, N. (1992), 'Economic experiments', Industrial and Corporate Change, 1 (1), 181203.

Schubert, T. (2010), 'Marketing and Organisational Innovations in Entrepreneurial Innovation Processes and their Relation to Market Structure and Firm Characteristics', Review of Industrial Organization, 36 (2), 189-212.

Stern, S. (2006), 'Economic experiments: The role of entrepreneurship in economic prosperity', Melbourne Review: A Journal of Business and Public Policy, 2 (2), 53.

Tether, B. S. and A. Tajar (2008), 'The organisational-cooperation mode of innovation and its prominence amongst European service firms', Research Policy, 37 (4), 720-739.

Wengel, J., G. Lay, A. Nylund, L. Bager-Sjögren, P. Stoneman, N. Bellini, A. Bonaccorsi and P. Shapira (2000), 'Analysis of empirical surveys on organisational innovation and lessons for future community innovation surveys', Scientific Follow-up of the Community Innovation Survey (CIS) Project CIS, 98 (191), 483.

Winter, S. G. (1984), 'Schumpeterian competition in alternative technological regimes', Journal of Economic Behavior \& Organization, 5 (3-4), 287-320. 
Table 1a. Number of new firms, exits, surviving firms, and relative rates, by entry cohort

\begin{tabular}{|r|r|r|r|r|r|} 
Cohort year & Cohorts - N & Exit - N & \multicolumn{1}{c|}{ Exit rate } & \multicolumn{1}{c|}{ Survival - N } & Survival rate \\
\hline 2001 & 325 & 224 & $68.92 \%$ & 101 & $31.08 \%$ \\
2002 & 278 & 205 & $73.74 \%$ & 73 & $26.26 \%$ \\
2003 & 309 & 201 & $65.05 \%$ & 108 & $34.95 \%$ \\
2004 & 301 & 187 & $62.13 \%$ & 114 & $37.87 \%$ \\
2005 & 449 & 303 & $67.48 \%$ & 146 & $32.52 \%$ \\
2006 & 667 & 431 & $64.62 \%$ & 236 & $35.38 \%$ \\
\hline & 2329 & 1551 & $66.60 \%$ & 778 & $33.40 \%$ \\
\hline
\end{tabular}

Table 1b. Means, standard deviations and correlation matrix

\begin{tabular}{|c|c|c|c|c|c|c|c|c|c|c|}
\hline VARIABLES & Mean & St. Dev. & Growth & Haltiw ind. & Group & Inn. & Product & Process & Organis. & Marke \\
\hline Growth rate & -0.219 & 1.152 & 1 & & & & & & & \\
\hline Haltiwanger ind. & -0.152 & 0.278 & 0.017 & 1 & & & & & & \\
\hline Group (exit) & 0.463 & 0.499 & 0.012 & $-0.037 *$ & 1 & & & & & \\
\hline Innovator & 0.532 & 0.499 & 0.018 & $-0.101^{*}$ & $0.112 *$ & 1 & & & & \\
\hline Product Inn. & 0.265 & 0.441 & $0.039 *$ & $-0.098^{*}$ & $0.064 *$ & $0.564 *$ & 1 & & & \\
\hline Process Inn. & 0.235 & 0.424 & 0.022 & $-0.047 *$ & $0.102 *$ & $0.520^{*}$ & $0.511 *$ & 1 & & \\
\hline Organisational Inn. & 0.376 & 0.485 & -0.009 & $-0.075^{*}$ & $0.115 *$ & $0.729 *$ & $0.318 *$ & $0.325 *$ & 1 & \\
\hline Marketing Inn. & 0.159 & 0.366 & $0.030 *$ & $-0.030 *$ & $0.059 *$ & $0.409 *$ & $0.351^{*}$ & $0.277 *$ & $0.358 *$ & 1 \\
\hline
\end{tabular}

Significance level at 0.05

Table 2. Life Tables

\begin{tabular}{llllllll} 
& & & & \multicolumn{2}{c}{ ALL EXITS } & & \multicolumn{2}{c}{ ACQUISITIONS } \\
t0 & t1 & Existing t0 & exits t0-t1 & hazard & & exits t0-t1 & hazard \\
\hline 01-gen-03 & 31-dic-03 & 2329 & 57 & .0247772 & & 27 & .0117366 \\
01-gen-04 & 31-dic-04 & 2272 & 57 & .0254067 & & 15 & .006686 \\
01-gen-05 & 31-dic-05 & 2215 & 97 & .0447727 & & 44 & .0203093 \\
01-gen-06 & 31-dic-06 & 2118 & 84 & .0404624 & & 10 & .004817 \\
01-gen-07 & 31-dic-07 & 2034 & 370 & .2001082 & & 79 & .0427258 \\
01-gen-08 & 31-dic-08 & 1664 & 162 & .1023373 & & 42 & .0265319 \\
01-gen-09 & 31-dic-09 & 1502 & 114 & .0788927 & & 31 & .0214533 \\
01-gen-10 & 31-dic-10 & 1388 & 306 & .2477733 & & 227 & .1838057 \\
01-gen-11 & 31-dic-11 & 1082 & 75 & .0718047 & & 25 & .0239349 \\
01-gen-12 & 31-dic-12 & 1007 & 70 & .0720165 & & 21 & .0216049 \\
01-gen-13 & 31-dic-13 & 937 & 64 & .0707182 & & 26 & .0287293 \\
01-gen-14 & 31-dic-14 & 873 & 52 & .0613932 & & 12 & .0141677 \\
01-gen-15 & 31-dic-15 & 821 & 37 & .0461059 & & 9 & .011215 \\
\hline
\end{tabular}


Figure 1. Hazard function and Cumulative hazard function across entry cohorts
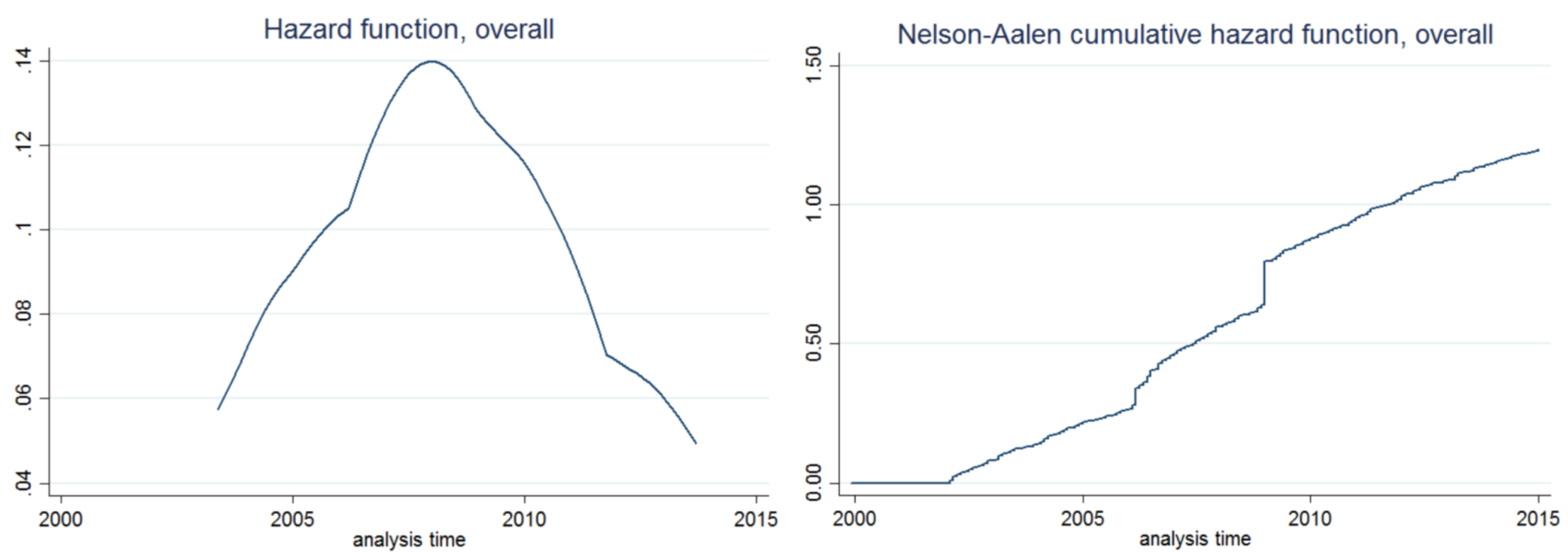
Figure 2. Kaplan-Meier survival functions by entry cohort
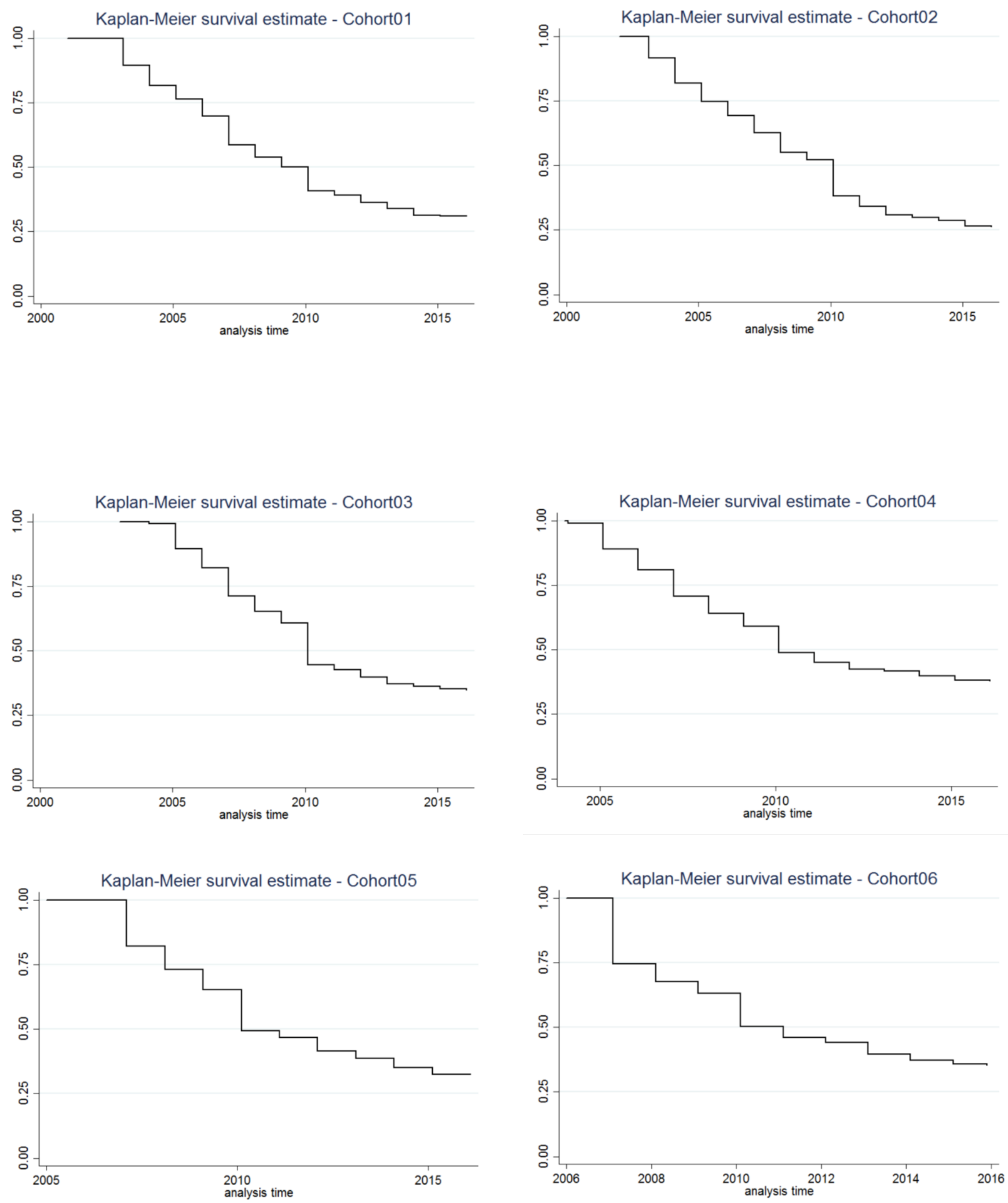
Table 3a. Piecewise exponential model of hazard rates, with time period-specific effects

Dep. Variable: hazard rate of exit

\begin{tabular}{|c|c|c|c|c|c|c|}
\hline VARIABLES & Mod.1 & Mod.2 & Mod.3 & Mod.4 & Mod.5 & Mod.6 \\
\hline Time-period 1 & $\begin{array}{l}-3.431^{* * *} \\
(0.377)\end{array}$ & $\begin{array}{l}-3.412^{* * *} \\
(0.377)\end{array}$ & $\begin{array}{l}-3.486^{* * *} \\
(0.377)\end{array}$ & $\begin{array}{l}-3.433^{* * *} \\
(0.382)\end{array}$ & $\begin{array}{l}-3.432^{* * *} \\
(0.382)\end{array}$ & $\begin{array}{l}-3.459^{* * *} \\
(0.377)\end{array}$ \\
\hline Time-period 2 & $\begin{array}{l}-2.275^{* * *} \\
(0.376)\end{array}$ & $\begin{array}{l}-2.258^{* * *} \\
(0.377)\end{array}$ & $\begin{array}{l}-2.332^{* * *} \\
(0.377)\end{array}$ & $\begin{array}{l}-2.277^{* * *} \\
(0.381)\end{array}$ & $\begin{array}{l}-2.276^{* * *} \\
(0.382)\end{array}$ & $\begin{array}{l}-2.302^{* * *} \\
(0.376)\end{array}$ \\
\hline Time-period 3 & $\begin{array}{l}-3.007^{* * *} \\
(0.382)\end{array}$ & $\begin{array}{l}-2.986^{* * *} \\
(0.382)\end{array}$ & $\begin{array}{l}-3.063^{* * *} \\
(0.382)\end{array}$ & $\begin{array}{l}-3.005^{* * *} \\
(0.386)\end{array}$ & $\begin{array}{l}-3.003^{* * *} \\
(0.387)\end{array}$ & $\begin{array}{l}-3.028^{* * *} \\
(0.381)\end{array}$ \\
\hline Growth rate & $\begin{array}{l}-0.0742^{* * *} \\
(0.0183)\end{array}$ & $\begin{array}{l}-0.0725^{* * *} \\
(0.0184)\end{array}$ & $\begin{array}{l}*-0.0740^{* * *} \\
(0.0184)\end{array}$ & $\begin{array}{l}{ }^{*}-0.0724^{* * *} \\
(0.0184)\end{array}$ & $\begin{array}{l}{ }^{*}-0.0727^{* * *} \\
(0.0184)\end{array}$ & $\begin{array}{c}-0.0739 * * * \\
(0.0185)\end{array}$ \\
\hline Group [exit] & $\begin{array}{l}0.772^{* * *} \\
(0.0549)\end{array}$ & $\begin{array}{l}0.765 * * * \\
(0.0546)\end{array}$ & $\begin{array}{l}0.770^{* * *} \\
(0.0548)\end{array}$ & $\begin{array}{l}0.772^{* * *} \\
(0.0547)\end{array}$ & $\begin{array}{l}0.773^{* * *} \\
(0.0548)\end{array}$ & $\begin{array}{l}0.773^{* * *} \\
(0.0549)\end{array}$ \\
\hline Haltiwanger ind. & $\begin{array}{l}0.0388 \\
(0.124)\end{array}$ & $\begin{array}{l}0.0381 \\
(0.124)\end{array}$ & $\begin{array}{l}0.0627 \\
(0.124)\end{array}$ & $\begin{array}{l}0.0421 \\
(0.124)\end{array}$ & $\begin{array}{l}0.0391 \\
(0.124)\end{array}$ & $\begin{array}{l}0.0437 \\
(0.125)\end{array}$ \\
\hline Innovator & $\begin{array}{l}-0.188^{* * *} \\
(0.0532)\end{array}$ & & & & & \\
\hline Product Inn. & & $\begin{array}{l}-0.231 * * * \\
(0.0637)\end{array}$ & & $\begin{array}{l}-0.175^{* *} \\
(0.0717)\end{array}$ & $\begin{array}{l}-0.170^{* *} \\
(0.0723)\end{array}$ & $\begin{array}{l}-0.197 * * * \\
(0.0738)\end{array}$ \\
\hline Process Inn. & & & $\begin{array}{l}-0.205^{* * *} \\
(0.0634)\end{array}$ & $\begin{array}{l}-0.123^{*} \\
(0.0712)\end{array}$ & $\begin{array}{l}-0.115 \\
(0.0723)\end{array}$ & $\begin{array}{l}-0.123^{*} \\
(0.0724)\end{array}$ \\
\hline Organizational Inn. & & & & & $\begin{array}{l}-0.0271 \\
(0.0559)\end{array}$ & $\begin{array}{l}-0.0527 \\
(0.0577)\end{array}$ \\
\hline Marketing Inn. & & & & & & $\begin{array}{l}0.126 * \\
(0.0766)\end{array}$ \\
\hline
\end{tabular}

Cohort and Sector dummies included

\begin{tabular}{lllllll}
\hline Observations & 5455 & 5455 & 5455 & 5455 & 5455 & 5455 \\
$\mathbf{n}^{\circ}$ firms & 2329 & 2329 & 2329 & 2329 & 2329 & 2329 \\
$\mathbf{n}^{\circ}$ exits & 1551 & 1551 & 1551 & 1551 & 1551 & 1551 \\
chi2 & 7811 & 7815 & 7805 & 7806 & 7809 & 7811 \\
p-value & 0.000 & 0.000 & 0.000 & 0.000 & 0.000 & 0.000 \\
log-likelihood & 1206 & 1207 & 1205 & 1208 & 1208 & 1210 \\
\hline
\end{tabular}

Clustered standard errors in parentheses. ${ }^{* *} p<0.01,{ }^{* *} p<0.05,{ }^{*} p<0.1$ 
Table 3b. Hazard ratios in the model formulations with time period-specific effects

\begin{tabular}{|c|c|c|c|c|c|c|}
\hline VARIABLES & Mod.1 & Mod.2 & Mod.3 & Mod.4 & Mod.5 & Mod.6 \\
\hline Innovator & $\begin{array}{l}0.829^{* * *} \\
(0.0441)\end{array}$ & & & & & \\
\hline Product Inn. & & $\begin{array}{l}0.794^{* * *} \\
(0.0505)\end{array}$ & & $\begin{array}{l}0.840^{* *} \\
(0.0602)\end{array}$ & $\begin{array}{l}0.843^{* *} \\
(0.0610)\end{array}$ & $\begin{array}{l}0.821^{* * *} \\
(0.0606)\end{array}$ \\
\hline Process Inn. & & & $\begin{array}{l}0.815^{* * *} \\
(0.0516)\end{array}$ & $\begin{array}{l}0.885^{*} \\
(0.0630)\end{array}$ & $\begin{array}{l}0.891 \\
(0.0644)\end{array}$ & $\begin{array}{l}0.884^{*} \\
(0.0640)\end{array}$ \\
\hline Organizational Inn. & & & & & $\begin{array}{l}0.973 \\
(0.0544)\end{array}$ & $\begin{array}{l}0.949 \\
(0.0547)\end{array}$ \\
\hline Marketing Inn. & & & & & & $\begin{array}{l}1.134 * \\
(0.0869)\end{array}$ \\
\hline Cohort and Sector a & ummies inc & ded & & & & \\
\hline Observations & 5445 & 5445 & 5445 & 5445 & 5445 & 5445 \\
\hline$n^{\circ}$ firms & 2329 & 2329 & 2329 & 2329 & 2329 & 2329 \\
\hline$n^{\circ}$ exits & 1551 & 1551 & 1551 & 1551 & 1551 & 1551 \\
\hline chi2 & 7811 & 7815 & 7805 & 7806 & 7809 & 7811 \\
\hline p-value & 0.000 & 0.000 & 0.000 & 0.000 & 0.000 & 0.000 \\
\hline log-likelihood & 1206 & 1207 & 1205 & 1208 & 1208 & 1210 \\
\hline
\end{tabular}

Clustered standard errors in parentheses. ${ }^{* * *} p<0.01,{ }^{* *} p<0.05,{ }^{*} p<0.1$ 
Table 4a. Piecewise exponential model of hazard rates with time period-specific effects

Dep. Variable: hazard rate of exit

\begin{tabular}{|c|c|c|c|c|c|c|c|}
\hline VARIABLES & Mod.7 & Mod.8 & Mod.9 & Mod.10 & Mod.11 & Mod.12 & Mod.13 \\
\hline Time-period 1 & $\begin{array}{l}-3.638 * * * \\
(0.374)\end{array}$ & $\begin{array}{l}-3.499 * * * \\
(0.373)\end{array}$ & $\begin{array}{l}-3.542^{* * * *} \\
(0.381)\end{array}$ & $\begin{array}{l}-3.522^{* * *} \\
(0.381)\end{array}$ & $\begin{array}{l}-3.629 * * * \\
(0.377)\end{array}$ & $\begin{array}{l}-3.532 * * * \\
(0.366)\end{array}$ & $\begin{array}{l}-3.637^{* * *} \\
(0.382)\end{array}$ \\
\hline Time-period 2 & $\begin{array}{l}-2.214 \cdots \cdots \\
(0.366)\end{array}$ & $\begin{array}{l}-2.247^{\cdots} \bullet \\
(0.370)\end{array}$ & $\begin{array}{l}-2.270 * * \\
(0.380)\end{array}$ & $\begin{array}{l}-2.224 \cdots \\
(0.378)\end{array}$ & $\begin{array}{l}-2.247^{\bullet \cdots} \\
(0.374)\end{array}$ & $\begin{array}{l}-2.338 \cdots \cdots \\
(0.363)\end{array}$ & $\begin{array}{l}-2.211^{* * *} \\
(0.378)\end{array}$ \\
\hline Time-period 3 & $\begin{array}{l}-3.107^{* *} \\
(0.380)\end{array}$ & $\begin{array}{l}-2.998 \cdots \cdots \\
(0.377)\end{array}$ & $\begin{array}{l}-3.113^{* * *} \\
(0.387)\end{array}$ & $\begin{array}{l}-3.041 * * \\
(0.386)\end{array}$ & $\begin{array}{l}-3.086^{* \cdots} \\
(0.383)\end{array}$ & $\begin{array}{l}-3.050^{* \cdots} \\
(0.369)\end{array}$ & $\begin{array}{l}-3.070 * * \\
(0.387)\end{array}$ \\
\hline Growth rate & $\begin{array}{l}-0.0740 \cdots \\
(0.0183)\end{array}$ & $\begin{array}{l}-0.0721 * \\
(0.0184)\end{array}$ & $\begin{array}{l}-0.0735 * \cdots \\
(0.0183)\end{array}$ & $\begin{array}{l}-0.0720 \cdots \\
(0.0183)\end{array}$ & $\begin{array}{l}-0.0760^{\cdots} \\
(0.0183)\end{array}$ & $\begin{array}{l}-0.0756^{* \cdots} \\
(0.0184)\end{array}$ & $\begin{array}{l}-0.0736 * \bullet \\
(0.0184)\end{array}$ \\
\hline Group [exit] & $\begin{array}{l}0.774 * * * \\
(0.0550)\end{array}$ & $\begin{array}{l}0.767^{\bullet \bullet} \\
(0.0547)\end{array}$ & $\begin{array}{l}0.768 \cdots \\
(0.0548)\end{array}$ & $\begin{array}{l}0.772 * \cdots \\
(0.0548)\end{array}$ & $\begin{array}{l}0.764 \cdots \\
(0.0549)\end{array}$ & $\begin{array}{l}0.755^{\bullet \cdots} \\
(0.0547)\end{array}$ & $\begin{array}{l}0.773^{* * *} \\
(0.0549)\end{array}$ \\
\hline Haltiwanger ind. & $\begin{array}{l}0.0395 \\
(0.124)\end{array}$ & $\begin{array}{l}0.0394 \\
(0.124)\end{array}$ & $\begin{array}{l}0.0646 \\
(0.124)\end{array}$ & $\begin{array}{l}0.0423 \\
(0.124)\end{array}$ & $\begin{array}{l}0.0575 \\
(0.124)\end{array}$ & $\begin{array}{l}0.0699 \\
(0.124)\end{array}$ & $\begin{array}{l}0.0446 \\
(0.124)\end{array}$ \\
\hline Innovator $x$ tp1 & $\begin{array}{l}0.162 \\
(0.115)\end{array}$ & & & & & & \\
\hline Innovator $x$ tp2 & $\begin{array}{l}-0.343^{\cdots} \cdots \\
(0.0664)\end{array}$ & & & & & & \\
\hline Innovator $x \operatorname{tp} 3$ & $\begin{array}{l}-0.0320 \\
(0.119)\end{array}$ & & & & & & \\
\hline Product Inn x tp1 & & $\begin{array}{l}0.0757 \\
(0.127)\end{array}$ & & $\begin{array}{l}0.00900 \\
(0.148)\end{array}$ & & & $\begin{array}{l}-0.0706 \\
(0.152)\end{array}$ \\
\hline Product Inn $x$ tp2 & & $\begin{array}{l}-0.332 \cdots \\
(0.0820)\end{array}$ & & $\begin{array}{l}-0.180 * \\
(0.0911)\end{array}$ & & & $\begin{array}{l}-0.202 * * \\
(0.0947)\end{array}$ \\
\hline Product Inn $x \operatorname{tp} 3$ & & $\begin{array}{l}-0.230^{\circ} \\
(0.134)\end{array}$ & & $\begin{array}{l}-0.358^{\bullet \bullet} \\
(0.154)\end{array}$ & & & $\begin{array}{l}-0.333^{* *} \\
(0.160)\end{array}$ \\
\hline Process Inn x tp1 & & & $\begin{array}{l}0.137 \\
(0.130)\end{array}$ & $\begin{array}{l}0.124 \\
(0.152)\end{array}$ & & & $\begin{array}{l}0.0488 \\
(0.154)\end{array}$ \\
\hline Process Inn $x$ tp2 & & & $\begin{array}{l}-0.420 * * * \\
(0.0853)\end{array}$ & $\begin{array}{l}-0.338 * \cdots \\
(0.0948)\end{array}$ & & & $\begin{array}{l}-0.308 * \cdots \\
(0.0953)\end{array}$ \\
\hline Process Inn $x \operatorname{tp} 3$ & & & $\begin{array}{l}0.0600 \\
(0.130)\end{array}$ & $\begin{array}{l}0.240 \\
(0.149)\end{array}$ & & & $\begin{array}{l}0.233 \\
(0.156)\end{array}$ \\
\hline Organiz Inn x tp1 & & & & & $\begin{array}{l}0.294 \cdots \\
(0.114)\end{array}$ & & $\begin{array}{l}0.273^{* *} \\
(0.125)\end{array}$ \\
\hline Organiz Inn x tp2 & & & & & $\begin{array}{l}-0.261 * * \\
(0.0695)\end{array}$ & & $\begin{array}{l}-0.202^{* * *} \\
(0.0743)\end{array}$ \\
\hline Organiz Inn $x$ tp3 & & & & & $\begin{array}{l}0.0240 \\
(0.120)\end{array}$ & & $\begin{array}{l}0.0630 \\
(0.131)\end{array}$ \\
\hline Marketing Inn x tp1 & & & & & & $\begin{array}{l}0.175 \\
(0.133)\end{array}$ & $\begin{array}{l}0.0528 \\
(0.145)\end{array}$ \\
\hline Marketing Inn $x$ tp2 & & & & & & $\begin{array}{l}-0.0229 \\
(0.0898)\end{array}$ & $\begin{array}{l}0.232^{* *} \\
(0.0995)\end{array}$ \\
\hline Marketing Inn $x$ tp3 & & & & & & $\begin{array}{l}-0.187 \\
(0.172)\end{array}$ & $\begin{array}{l}-0.153 \\
(0.188)\end{array}$ \\
\hline
\end{tabular}

Cohort and Sector dummies included

\begin{tabular}{llllllll}
\hline Observations & 5445 & 5445 & 5445 & 5445 & 5445 & 5445 & 5445 \\
$\mathrm{n}^{\circ}$ firms & 2329 & 2329 & 2329 & 2329 & 2329 & 2329 & 2329 \\
$\mathrm{n}^{\circ}$ exits & 1551 & 1551 & 1551 & 1551 & 1551 & 1551 & 1551 \\
chi2 & 7834 & 7825 & 7817 & 7806 & 7836 & 7831 & 7811 \\
p-value & 0.000 & 0.000 & 0.000 & 0.000 & 0.000 & 0.000 & 0.000 \\
log-likelihood & 1214 & 1210 & 1214 & 1219 & 1210 & 1201 & 1226 \\
\hline
\end{tabular}

Clustered standard errors in parentheses. $* *$ p<0.01, $*$ p<0.05, $\bullet p<0.1$ 
Table 4b. Hazard ratios in the model formulations with time period-specific effects

\begin{tabular}{|c|c|c|c|c|c|c|c|}
\hline VARIABLES & Mod.7 & Mod.8 & Mod.9 & Mod.10 & Mod.11 & Mod.12 & Mod.13 \\
\hline Innovator x tp1 & $\begin{array}{l}1.176 \\
(0.135)\end{array}$ & & & & & & \\
\hline Innovator $x$ tp2 & $\begin{array}{l}0.710^{* * *} \\
(0.0471)\end{array}$ & & & & & & \\
\hline Innovator $x \operatorname{tp} 3$ & $\begin{array}{l}0.969 \\
(0.115)\end{array}$ & & & & & & \\
\hline Product Inn $x$ tp1 & & $\begin{array}{l}1.079 \\
(0.137)\end{array}$ & & $\begin{array}{l}1.009 \\
(0.149)\end{array}$ & & & $\begin{array}{l}0.932 \\
(0.141)\end{array}$ \\
\hline Product Inn $x$ tp2 & & $\begin{array}{l}0.717^{* * *} \\
(0.0588)\end{array}$ & & $\begin{array}{l}0.835^{* *} \\
(0.0760)\end{array}$ & & & $\begin{array}{l}0.817^{* *} \\
(0.0773)\end{array}$ \\
\hline Product Inn $x$ tp 3 & & $\begin{array}{l}0.794^{*} \\
(0.107)\end{array}$ & & $\begin{array}{l}0.699^{* *} \\
(0.108)\end{array}$ & & & $\begin{array}{l}0.717^{* *} \\
(0.115)\end{array}$ \\
\hline Process Inn x tp1 & & & $\begin{array}{l}1.147 \\
(0.149)\end{array}$ & $\begin{array}{l}1.132 \\
(0.172)\end{array}$ & & & $\begin{array}{l}1.050 \\
(0.162)\end{array}$ \\
\hline Process Inn x tp2 & & & $\begin{array}{l}0.657^{* * *} \\
(0.0561)\end{array}$ & $\begin{array}{l}0.713^{* * *} \\
(0.0676)\end{array}$ & & & $\begin{array}{l}0.735^{* * *} \\
(0.0701)\end{array}$ \\
\hline Process Inn x tp3 & & & $\begin{array}{l}1.062 \\
(0.139)\end{array}$ & $\begin{array}{l}1.272 \\
(0.190)\end{array}$ & & & $\begin{array}{l}1.262 \\
(0.197)\end{array}$ \\
\hline Organiz Inn x tp1 & & & & & $\begin{array}{l}1.341^{* * *} \\
(0.152)\end{array}$ & & $\begin{array}{l}1.314^{* *} \\
(0.164)\end{array}$ \\
\hline Organiz Inn x tp2 & & & & & $\begin{array}{l}0.770^{* * *} \\
(0.0535)\end{array}$ & & $\begin{array}{l}0.817^{* * *} \\
(0.0607)\end{array}$ \\
\hline Organiz Inn x tp3 & & & & & $\begin{array}{l}1.024 \\
(0.123)\end{array}$ & & $\begin{array}{l}1.065 \\
(0.139)\end{array}$ \\
\hline Marketing Inn $x$ tp1 & & & & & & $\begin{array}{l}1.191 \\
(0.159)\end{array}$ & $\begin{array}{l}1.054 \\
(0.153)\end{array}$ \\
\hline Marketing Inn $x$ tp2 & & & & & & $\begin{array}{l}0.977 \\
(0.0878)\end{array}$ & $\begin{array}{l}1.261^{* *} \\
(0.125)\end{array}$ \\
\hline Marketing Inn $x$ tp3 & & & & & & $\begin{array}{l}0.830 \\
(0.143)\end{array}$ & $\begin{array}{l}0.858 \\
(0.161)\end{array}$ \\
\hline
\end{tabular}

Cohort and Sector dummies included

\begin{tabular}{llllllll}
\hline Observations & 5445 & 5445 & 5445 & 5445 & 5445 & 5445 & 5445 \\
$\mathrm{n}^{\circ}$ firms & 2329 & 2329 & 2329 & 2329 & 2329 & 2329 & 2329 \\
$\mathrm{n}^{\circ}$ exits & 1551 & 1551 & 1551 & 1551 & 1551 & 1551 & 1551 \\
chi2 & 7834 & 7825 & 7817 & 7806 & 7836 & 7831 & 7811 \\
p-value & 0.000 & 0.000 & 0.000 & 0.000 & 0.000 & 0.000 & 0.000 \\
log-likelihood & 1214 & 1210 & 1214 & 1219 & 1210 & 1201 & 1226 \\
\hline
\end{tabular}

Clustered standard errors in parentheses. ${ }^{* * *} p<0.01,{ }^{* *} p<0.05,{ }^{*} p<0.1$ 
Table 5. Piecewise exponential model of hazard rates with time period-specific effects, and with M\&A as the only type of exit

\begin{tabular}{|c|c|c|c|c|c|c|}
\hline VARIABLES & Mod.1 & Mod.2 & Mod.3 & Mod.4 & Mod.5 & Mod.6 \\
\hline Time-period 1 & $\begin{array}{l}-6.404^{* * *} \\
(0.938)\end{array}$ & $\begin{array}{l}-6.347^{* * *} \\
(0.934)\end{array}$ & $\begin{array}{l}-6.452^{* * *} \\
(0.940)\end{array}$ & $\begin{array}{l}-6.384^{* * *} \\
(0.935)\end{array}$ & $\begin{array}{l}-6.379 * * * \\
(0.933)\end{array}$ & $\begin{array}{l}-6.408 * * * \\
(0.936)\end{array}$ \\
\hline Time-period 2 & $\begin{array}{l}-4.911 * * * \\
(0.935)\end{array}$ & $\begin{array}{l}-4.853^{* * *} \\
(0.930)\end{array}$ & $\begin{array}{l}-4.959 * * * \\
(0.937)\end{array}$ & $\begin{array}{l}-4.888^{* * *} \\
(0.932)\end{array}$ & $\begin{array}{l}-4.883^{* * *} \\
(0.930)\end{array}$ & $\begin{array}{l}-4.910 * * * \\
(0.933)\end{array}$ \\
\hline Time-period 3 & $\begin{array}{l}-5.729 * * * \\
(0.939)\end{array}$ & $\begin{array}{l}-5.657^{* * *} \\
(0.934)\end{array}$ & $\begin{array}{l}-5.769 * * * \\
(0.941)\end{array}$ & $\begin{array}{l}-5.686^{* * *} \\
(0.936)\end{array}$ & $\begin{array}{l}-5.681^{* * *} \\
(0.934)\end{array}$ & $\begin{array}{l}-5.705^{* * *} \\
(0.937)\end{array}$ \\
\hline Growth rate & $\begin{array}{l}0.00153 \\
(0.0331)\end{array}$ & $\begin{array}{l}0.0102 \\
(0.0330)\end{array}$ & $\begin{array}{l}0.00385 \\
(0.0332)\end{array}$ & $\begin{array}{l}0.00964 \\
(0.0332)\end{array}$ & $\begin{array}{l}0.00830 \\
(0.0334)\end{array}$ & $\begin{array}{l}0.00737 \\
(0.0335)\end{array}$ \\
\hline Group [exit] & $\begin{array}{l}2.226 * * * \\
(0.123)\end{array}$ & $\begin{array}{l}2.225 * * * \\
(0.123)\end{array}$ & $\begin{array}{l}2.234 * * * \\
(0.123)\end{array}$ & $\begin{array}{l}2.241 * * * \\
(0.123)\end{array}$ & $\begin{array}{l}2.246 * * * \\
(0.123)\end{array}$ & $\begin{array}{l}2.245 * * * \\
(0.123)\end{array}$ \\
\hline Haltiwanger ind. & $\begin{array}{l}-0.0941 \\
(0.206)\end{array}$ & $\begin{array}{l}-0.103 \\
(0.205)\end{array}$ & $\begin{array}{l}-0.0593 \\
(0.206)\end{array}$ & $\begin{array}{l}-0.0940 \\
(0.205)\end{array}$ & $\begin{array}{l}-0.109 \\
(0.205)\end{array}$ & $\begin{array}{l}-0.107 \\
(0.206)\end{array}$ \\
\hline Innovator & $\begin{array}{l}-0.245 * * * \\
(0.0860)\end{array}$ & & & & & \\
\hline Product Inn. & & $\begin{array}{l}-0.471 * * * \\
(0.110)\end{array}$ & & $\begin{array}{l}-0.342^{* * *} \\
(0.123)\end{array}$ & $\begin{array}{l}-0.329 * * * \\
(0.124)\end{array}$ & $\begin{array}{l}-0.359 * * * \\
(0.128)\end{array}$ \\
\hline Process Inn. & & & $\begin{array}{l}-0.441 * * * \\
(0.109)\end{array}$ & $\begin{array}{l}-0.289^{* *} \\
(0.122)\end{array}$ & $\begin{array}{l}-0.261^{* *} \\
(0.125)\end{array}$ & $\begin{array}{l}-0.266 * * \\
(0.125)\end{array}$ \\
\hline \multicolumn{2}{|l|}{ Organizational Inn. } & & & & $\begin{array}{l}-0.0982 \\
(0.0901)\end{array}$ & $\begin{array}{l}-0.128 \\
(0.0926)\end{array}$ \\
\hline \multicolumn{2}{|l|}{ Marketing Inn. } & & & & & $\begin{array}{l}0.133 \\
(0.122)\end{array}$ \\
\hline \multicolumn{7}{|c|}{ Cohort and Sector dummies included } \\
\hline Observations & 5455 & 5455 & 5455 & 5455 & 5455 & 5455 \\
\hline$n^{\circ}$ firms & 2329 & 2329 & 2329 & 2329 & 2329 & 2329 \\
\hline$n^{\circ}$ exits & 568 & 568 & 568 & 568 & 568 & 568 \\
\hline chi2 & 4922 & 4918 & 4905 & 4902 & 4906 & 4910 \\
\hline p-value & 0.000 & 0.000 & 0.000 & 0.000 & 0.000 & 0.000 \\
\hline log-likelihood & 117.6 & 123.7 & 122.5 & 126.6 & 127.2 & 127.7 \\
\hline
\end{tabular}

Clustered standard errors in parentheses.*** $p<0.01, * * p<0.05, * p<0.1$ 
Table 6. Piecewise exponential model of hazard rates with time period-specific effects, and with M\&A as the only type of exit

\begin{tabular}{|c|c|c|c|c|c|c|c|}
\hline VARIABLES & Mod.7 & Mod.8 & Mod.9 & Mod.10 & Mod.11 & Mod.12 & Mod.13 \\
\hline \multirow[t]{2}{*}{ Time-period 1} & $-6.623^{* * *}$ & $-6.448^{* * *}$ & $-6.459 * * *$ & $-6.462^{* * *}$ & $-6.559 * * *$ & $-6.473^{* * *}$ & $-6.582^{* * *}$ \\
\hline & $(0.927)$ & $(0.935)$ & $(0.928)$ & $(0.926)$ & $(0.924)$ & $(0.943)$ & $(0.919)$ \\
\hline \multirow[t]{2}{*}{ Time-period 2} & $-5.915^{* * *}$ & $-5.648^{* * *}$ & $-5.869 * * *$ & $-5.763^{* * *}$ & $-5.878^{* * *}$ & $-5.767^{* * *}$ & $-5.858^{* * *}$ \\
\hline & $(0.927)$ & $(0.934)$ & $(0.929)$ & $(0.926)$ & $(0.926)$ & $(0.940)$ & $(0.921)$ \\
\hline \multirow[t]{2}{*}{ Time-period 3} & $-4.829 * * *$ & $-4.861^{* * *}$ & $-4.880 * * *$ & $-4.844 * * *$ & $-4.827^{* * *}$ & $-4.909 * * *$ & $-4.806^{* * *}$ \\
\hline & $(0.917)$ & $(0.930)$ & $(0.924)$ & $(0.921)$ & $(0.919)$ & $(0.937)$ & $(0.913)$ \\
\hline \multirow[t]{2}{*}{ Growth rate } & 0.00146 & 0.0109 & 0.00348 & 0.00993 & -0.00184 & 0.00143 & 0.00843 \\
\hline & $(0.0330)$ & $(0.0329)$ & $(0.0331)$ & $(0.0332)$ & $(0.0333)$ & $(0.0328)$ & $(0.0335)$ \\
\hline \multirow[t]{2}{*}{ Group [exit] } & $2.222^{* * *}$ & $2.229^{* * *}$ & $2.226^{* * *}$ & $2.237^{* * *}$ & $2.216^{* * *}$ & $2.207^{* * *}$ & $2.240^{* * *}$ \\
\hline & $(0.123)$ & $(0.123)$ & $(0.123)$ & $(0.124)$ & $(0.122)$ & $(0.123)$ & $(0.123)$ \\
\hline \multirow[t]{2}{*}{ Haltiwanger ind. } & -0.0906 & -0.103 & -0.0575 & -0.0958 & -0.0803 & -0.0565 & -0.109 \\
\hline & $(0.205)$ & $(0.205)$ & $(0.206)$ & $(0.205)$ & $(0.206)$ & $(0.206)$ & $(0.205)$ \\
\hline \multirow[t]{2}{*}{ Innovator x tp1 } & 0.157 & & & & & & \\
\hline & $(0.208)$ & & & & & & \\
\hline \multirow[t]{2}{*}{ Innovator x tp2 } & 0.0591 & & & & & & \\
\hline & $(0.227)$ & & & & & & \\
\hline \multirow[t]{2}{*}{ Innovator $x \operatorname{tp} 3$} & $-0.414^{* * *}$ & & & & & & \\
\hline & $(0.0983)$ & & & & & & \\
\hline \multirow[t]{2}{*}{ Product Inn x tp1 } & & -0.0882 & & 0.00531 & & & -0.0837 \\
\hline & & $(0.240)$ & & $(0.289)$ & & & $(0.305)$ \\
\hline \multirow[t]{2}{*}{ Product Inn x tp2 } & & $-0.591^{* *}$ & & $-0.814^{* * *}$ & & & $-0.871^{* * *}$ \\
\hline & & $(0.257)$ & & $(0.300)$ & & & $(0.314)$ \\
\hline \multirow[t]{2}{*}{ Product Inn x tp3 } & & $-0.538^{* * *}$ & & $-0.306^{* *}$ & & & $-0.292 * *$ \\
\hline & & $(0.131)$ & & $(0.142)$ & & & $(0.147)$ \\
\hline \multirow[t]{2}{*}{ Process Inn x tp1 } & & & -0.185 & -0.208 & & & -0.281 \\
\hline & & & $(0.258)$ & $(0.310)$ & & & $(0.318)$ \\
\hline \multirow[t]{2}{*}{ Process Inn x tp2 } & & & 0.0477 & 0.421 & & & 0.356 \\
\hline & & & $(0.231)$ & $(0.268)$ & & & $(0.288)$ \\
\hline \multirow[t]{2}{*}{ Process Inn x tp3 } & & & $-0.676^{* * *}$ & $-0.547^{* * *}$ & & & $-0.472^{* * *}$ \\
\hline & & & $(0.138)$ & $(0.151)$ & & & $(0.153)$ \\
\hline \multirow[t]{2}{*}{ Organiz Inn x tp1 } & & & & & 0.187 & & 0.209 \\
\hline & & & & & $(0.205)$ & & $(0.232)$ \\
\hline \multirow[t]{2}{*}{ Organiz Inn x tp2 } & & & & & 0.139 & & 0.168 \\
\hline & & & & & $(0.215)$ & & $(0.235)$ \\
\hline \multirow[t]{2}{*}{ Organiz Inn x tp3 } & & & & & $-0.439 * * *$ & & $-0.305^{* * *}$ \\
\hline & & & & & $(0.106)$ & & $(0.113)$ \\
\hline \multirow[t]{2}{*}{ Marketing Inn x tp1 } & & & & & & 0.158 & 0.138 \\
\hline & & & & & & $(0.238)$ & $(0.258)$ \\
\hline \multirow[t]{2}{*}{ Marketing Inn x tp2 } & & & & & & -0.0465 & 0.128 \\
\hline & & & & & & $(0.286)$ & $(0.325)$ \\
\hline \multirow[t]{2}{*}{ Marketing Inn x tp3 } & & & & & & $-0.237^{*}$ & 0.124 \\
\hline & & & & & & $(0.144)$ & $(0.154)$ \\
\hline
\end{tabular}

Cohort and Sector dummies included

\begin{tabular}{llllllll}
\hline Observations & 5445 & 5445 & 5445 & 5445 & 5445 & 5445 & 5445 \\
$\mathbf{n}^{\circ}$ firms & 2329 & 2329 & 2329 & 2329 & 2329 & 2329 & 2329 \\
$\mathbf{n}^{\circ}$ exits & 568 & 568 & 568 & 568 & 568 & 568 & 568 \\
chi2 & 4919 & 4918 & 4906 & 4896 & 4936 & 4932 & 4908 \\
p-value & 0.000 & 0.000 & 0.000 & 0.000 & 0.000 & 0.000 & 0.000 \\
log-likelihood & 121.9 & 125.1 & 126.7 & 133.3 & 122.5 & 115.4 & 137.7 \\
\hline
\end{tabular}

Clustered standard errors in parentheses. ${ }^{* * *} p<0.01,{ }^{* *} p<0.05,{ }^{*} p<0.1$ 


\section{Footnotes}

${ }^{1}$ In our dataset, a firm exiting as a subsidiary is necessarily also a firm born as a subsidiary, because, otherwise we would have observed its exit as an 'exit by acquisition'. If it was born as an independent firm, it had to be acquired before becoming a subsidiary of an existing firm.

${ }^{2}$ The hazard rate is also called a "(conditional) failure rate" since the denominator (i.e., the population survivors) converts the expression into a conditional rate, given survival past time: $\mathrm{h}(\mathrm{t})=$ $\mathrm{f}(\mathrm{t}) / 1-\mathrm{F}(\mathrm{t})$ where $1-\mathrm{F}(\mathrm{t})$ is the population survivors. We will refer to the hazard rate in the text also as exit rate (instead of failure rate) to highlight that we do observe firms' exits of the markets that do not always coincide with firms' failure.

${ }^{3}$ It is worth noting that despite the predictor variables for the introduction of product and process innovations display the highest correlation between innovation types (equal to 0.511 in Table 1b), the estimated coefficients and standard errors remain relatively stable in Model 4, in which both predictors are entered simultaneously, as compared to Models 2 and 3, in which one or the other predictor is removed from the equation. This confirms that the correlation between the two predictors does not raise concerns for multicollinearity. 